Review

\title{
Piezoelectric Energy Harvesting Solutions
}

\section{Renato Caliò ${ }^{1}$ *, Udaya Bhaskar Rongala ${ }^{1}$, Domenico Camboni ${ }^{1}$, Mario Milazzo ${ }^{1}$, Cesare Stefanini ${ }^{1}$, Gianluca de Petris ${ }^{2}$ and Calogero Maria Oddo ${ }^{1} *$}

1 The BioRobotics Institute, Scuola Superiore Sant'Anna, Polo Sant'Anna Valdera, Viale Rinaldo Piaggio 34, Pontedera 56025, PISA, Italy; E-Mails: u.rongala@ sssup.it (U.B.R.); d.camboni@sssup.it (D.C.); m.milazzo@sssup.it (M.M.); c.stefanini@sssup.it (C.S.) Telecom Italia, WHITE Lab, Via Cardinale Maffi 27, Pisa 56126, PISA, Italy; E-Mail: gianluca.depetris@ telecomitalia.it

* Authors to whom correspondence should be addressed; E-Mails: r.calio@ sssup.it (R.C.); oddoc@sssup.it (C.M.O.); Tel.: +39-050-883-067 (C.M.O.); Fax: +39-050-883-101 (C.M.O.).

Received: 1 November 2013; in revised form: 18 February 2014 / Accepted: 24 February 2014 / Published: 10 March 2014

\begin{abstract}
This paper reviews the state of the art in piezoelectric energy harvesting. It presents the basics of piezoelectricity and discusses materials choice. The work places emphasis on material operating modes and device configurations, from resonant to non-resonant devices and also to rotational solutions. The reviewed literature is compared based on power density and bandwidth. Lastly, the question of power conversion is addressed by reviewing various circuit solutions.
\end{abstract}

Keywords: energy harvesting; piezoelectric generator; power management; MEMS; wearable technology

\section{Introduction}

Energy harvesting or energy scavenging is the process of extracting small amount of energy from ambient environment through various sources of energy. The available energy for harvesting is mainly provided by ambient light (artificial and natural lighting), ambient radio frequency, thermal sources and mechanical sources.

Reduction in size and energetic demands of sensors, and the low power consumption trend in CMOS electronic circuitry opened novel research lines on battery recharge via available power 
sources. Harvesters can be employed as battery rechargers in various environments, such as industries, houses [1,2], the military (as for unmanned aerial vehicles [3]) and handheld or wearable devices [4-9]. The possibility to avoid replacing exhausted batteries is highly attractive for wireless networks (Wireless Sensor Networks [10]), in which the maintenance costs due to battery check and replacement are relevant. Another emerging field of application is biomedical systems, where the energy could be harvested from an off-the-shelf piezoelectric unit and used to implement drug delivery systems [11] or tactile sensors [12-14]. Recent research also includes energy conversion from the occlusal contact during chewing by means of a piezoelectric layer [11,15] and from heart beats [16].

We can classify the main energy harvesting technologies by the hierarchy shown in Figure 1. Motion harvester systems can be structured as follows: the harvester collects inputs through its frame, directly connected to the hosting structure and to the transducer; at the end of the system chain, a conditioning circuit manipulates the electrical signals. This paper specifically focuses on piezoelectric motion harvesting techniques.

Figure 1. Hierarchy of main energy harvesting technologies.

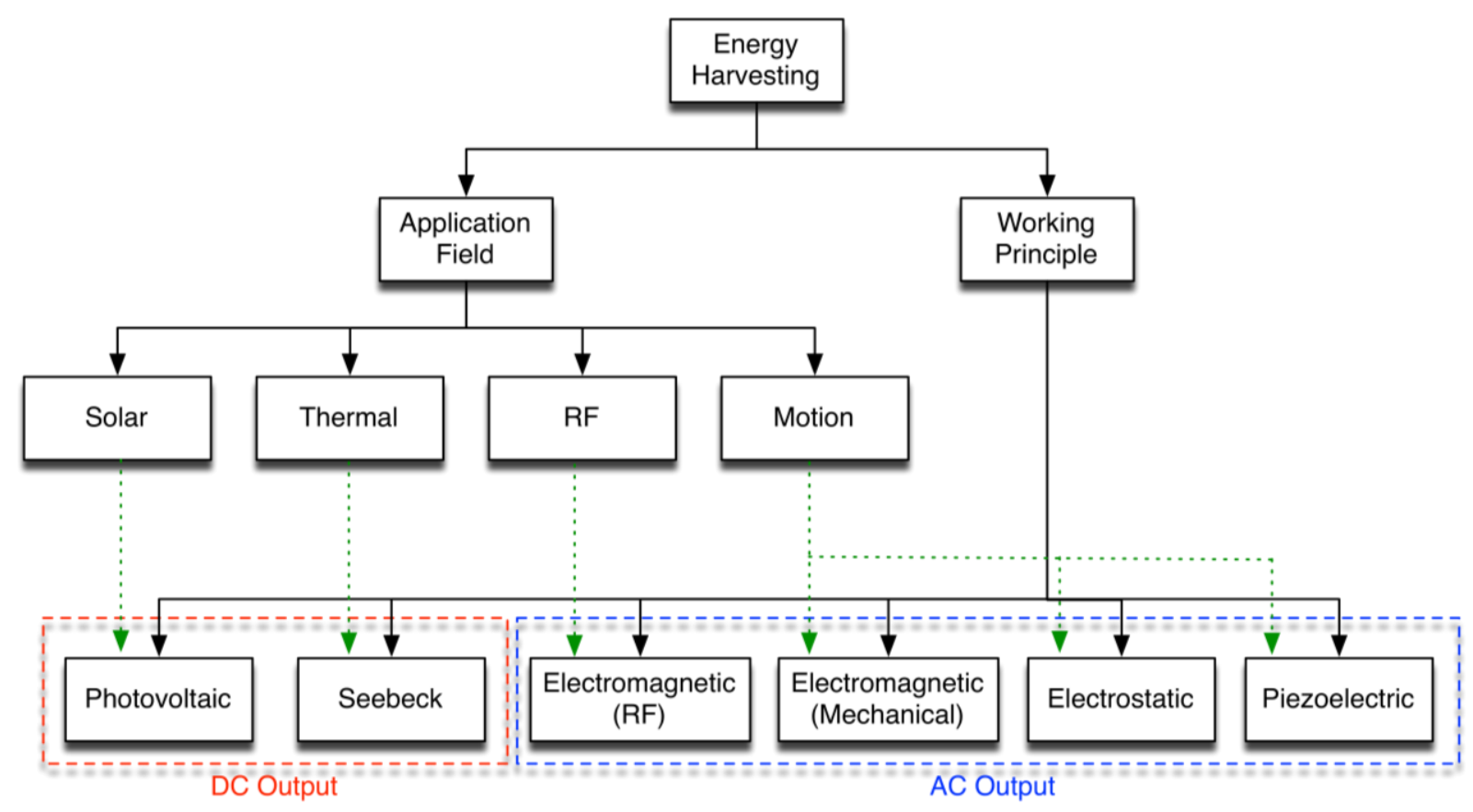

The possibility and the effectiveness of extracting energy from human activities has been under study for years [17]. As a matter of fact, continuous and uninterrupted power can potentially be available: from typing $(\sim \mathrm{mW})$, motion of upper limbs $(\sim 10 \mathrm{~mW})$, air exhalation while breathing $(\sim 100 \mathrm{~mW})$, walking $(\sim \mathrm{W})[18,19]$ (Figure 2$)$, and in this work we review state of the art of motion based energy harvesting.

Among available motion based harvesting techniques, piezoelectric transduction offers higher power densities [20] in comparison to electrostatic transduction (which also needs an initial polarization). Also, piezoelectric technologies are better suited than electromagnetic ones for MEMS implementation, because of the limitations in magnets miniaturization with current state-of-the-art microfabrication processes [21]. 
Figure 2. Estimation of available power that could be harvested during human activities (Adapted from [22]).

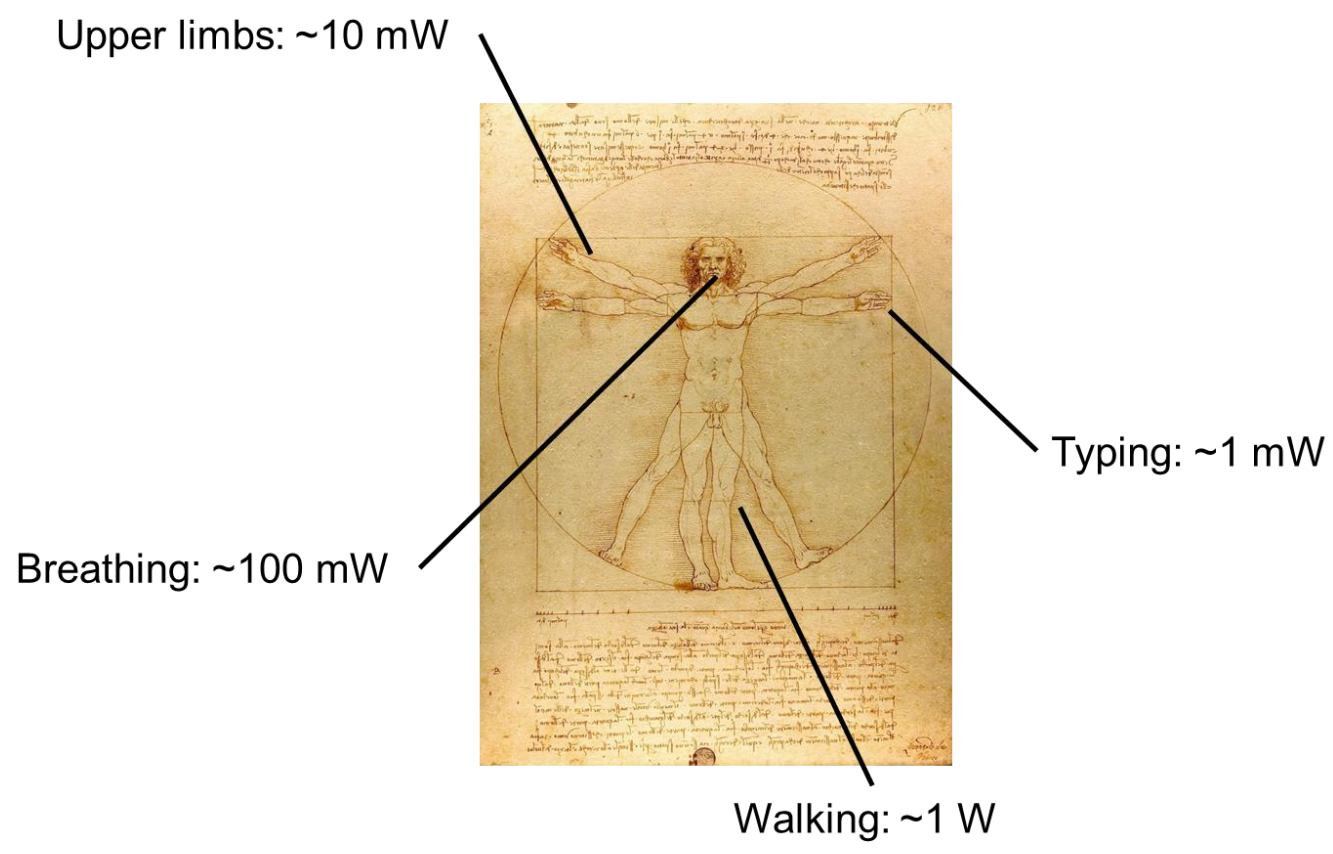

\section{Transduction Principle}

The piezoelectric effect converts mechanical strain into electric current or voltage. It is based on the fundamental structure of a crystal lattice. Certain crystalline structures have a charge balance with negative and positive polarization, which neutralize along the imaginary polar axis. When this charge balance is perturbed with external stress onto the crystal mesh, the energy is transferred by electric charge carriers creating a current in the crystal. Conversely, with the piezoelectric effect an external charge input will create an unbalance in the neutral charge state causing mechanical stress.

The connection between piezoelectricity and crystal symmetry are closely established. The piezoelectric effect is observed in crystals without center of symmetry, and the relationship can be explained with monocrystal and polycrystalline structures.

In a monocrystal (Figure 3) the polar axes of all of the charge carriers exhibit one-way directional characteristics. These crystals demonstrate symmetry, where the polar axes throughout the crystal would lie unidirectional even if it was split into pieces.

Figure 3. Monocrystal.

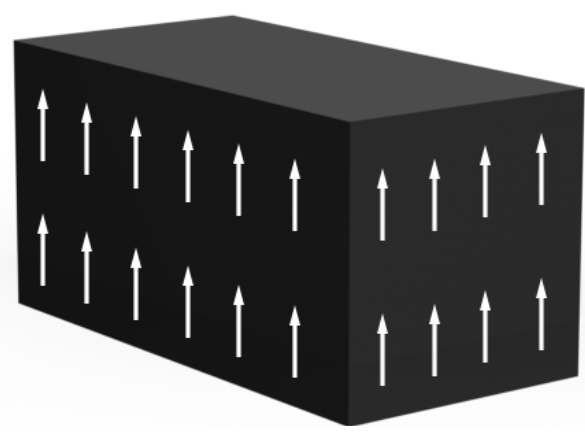


Instead, a polycrystal (Figure 4) is characterized by different regions within the material with different polar axes. It is asymmetrical because there is no point at which the crystal could be cut that would leave the two remaining pieces with the same resultant polar axes.

In order to attain the piezoelectric effect, the polycrystal is heated to the Curie point along with strong electric field. The heat allows the molecules to move more freely and the electric field forces the dipoles to rearrange in accordance with the external field (Figure 5).

Figure 4. Polycrystal.

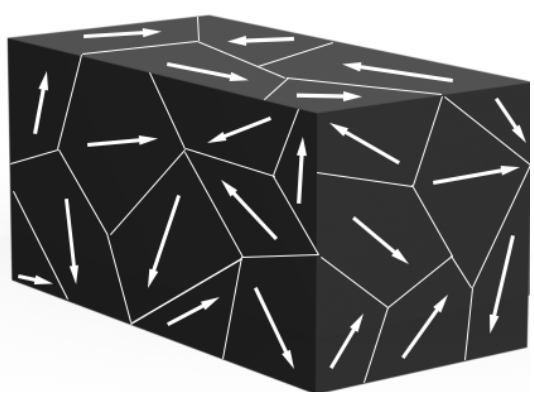

Figure 5. (a) Polarizations; (b) Surviving Polarity.

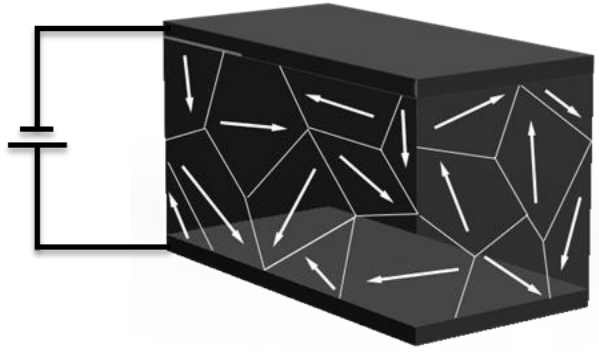

(a)

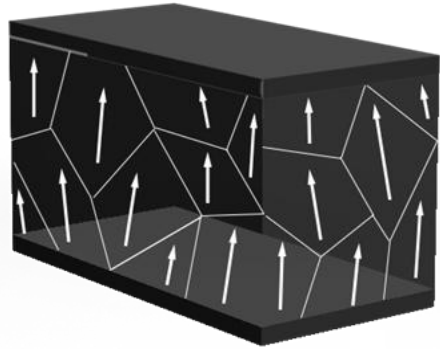

(b)

As a result, the material possesses piezoelectric effect: a voltage of the same polarity as of the poling voltage appears between electrodes when the material is compressed; and opposite polarity appears when stretched. Material deformation takes place when a voltage difference is applied, and if an AC signal is applied the material will vibrate at the same frequency as the signal [23-25].

Piezoelectricity is governed by the following constitutive equations, which link the stress $T$, the strain $S$, the electric field $E$ and the electrical induction $D$ :

$$
\left\{\begin{array}{c}
T_{p}=c_{p q}^{E} S_{q}-e_{k p} E_{k} \\
D_{i}=e_{i q} S_{q}+\varepsilon_{i k}^{S} E_{k}
\end{array}\right.
$$

where $c_{p q}^{E}$ is the Young's modulus, $e_{k p}$ is the piezoelectric coefficient and $\varepsilon_{i k}^{S}$ is the clamped permittivity. The same relationship can be written in other three forms, depending on the couple of variable (among $T, S, E$ and $D$ ) chosen to be independent [26]. The superscript $E$ indicates a constant electric field (which corresponds for example to a short circuit condition, where $E=0$ ), as well as the superscript $S$ stands for a condition of constant strain.

For each couple of constitutive equations there is a different piezoelectric coefficient, defined as: 


$$
\begin{gathered}
e_{i p} \triangleq\left(\frac{\delta D_{i}}{\delta S_{p}}\right)^{E}=-\left(\frac{\delta T_{p}}{\delta E_{i}}\right)^{S} \\
d_{i p} \triangleq\left(\frac{\delta D_{i}}{\delta T_{p}}\right)^{E}=\left(\frac{\delta S_{p}}{\delta E_{i}}\right)^{T} \\
g_{i p} \triangleq-\left(\frac{\delta E_{i}}{\delta T_{p}}\right)^{D}=\left(\frac{\delta S_{p}}{\delta D_{i}}\right)^{T} \\
h_{i p} \triangleq-\left(\frac{\delta E_{i}}{\delta S_{p}}\right)^{D}=-\left(\frac{\delta T_{p}}{\delta D_{i}}\right)^{S}
\end{gathered}
$$

Related to each other as follows:

$$
\begin{gathered}
d_{i p}=\varepsilon_{i k}^{T} g_{k p} \\
e_{i p}=d_{i q} c_{q p}^{E} \\
g_{i p}=d_{k p} / \varepsilon_{i k}^{T} \\
h_{i p}=g_{i q} c_{q p}^{D}
\end{gathered}
$$

An important parameter is the electromechanical coupling factor, $k_{i q}$, which describes the conversion between mechanical and electrical energy. It can be written in terms of coefficients of the material:

$$
k_{i q}^{2} \triangleq \frac{W_{i}^{(\text {electrical })}}{W_{q}^{(\text {mechanical })}}=\frac{e_{i q}^{2}}{\varepsilon_{i k}^{T} c_{p q}^{E}}=\frac{e_{i q}^{2}}{\varepsilon_{i k}^{S} c_{p q}^{E}+e_{i q}^{2}}
$$

The efficiency of energy conversion, $\eta$, is described, at resonance, as follows:

$$
\eta=\frac{\frac{k^{2}}{2\left(1-k^{2}\right)}}{\frac{1}{Q}+\frac{k^{2}}{2\left(1-k^{2}\right)}}
$$

where, $k^{2}$ is the coupling factor as defined in Equation (4) and $\mathrm{Q}$ is the quality factor of the generator [21,27].

To understand how the electrical quantities $(V$ and $I$ ) are related to the mechanical ones (force $F$ and displacement $z$ ), the particular case of a piezoelectric disk can be considered. In this case, from Equation (1) the following relationships can be obtained [28]:

$$
\left\{\begin{array}{l}
F_{P}=k_{P E} Z+\alpha V \\
I_{p}=\alpha \dot{z}-C_{p} \frac{d V}{d t}
\end{array}\right.
$$

In which the featuring quantities are the restoring force $F_{P}$ of the piezoelectric material, its stiffness when it is short-circuited $k_{P E}$, the displacement $z$, the force factor $\alpha$, the voltage across the electrodes $V$ and the outgoing current $I_{p}$, and the clamped capacitance $C_{p}$. These equations are derived considering the following approximations:

$$
E=-\frac{V}{H} ; S=\frac{z}{H} ; I_{p}=A \frac{d D}{d t} ; F_{P}=A T_{p}
$$

and the featured quantities can be written as: 


$$
k_{P E}=\frac{c_{p q}^{E} A}{H} ; C_{p}=\frac{\varepsilon_{i k}^{S} A}{H} ; \alpha=\frac{e_{i q} A}{H}
$$

where, $A$ and $H$ are the section and thickness of the piezoelectric disk.

In a more generic case of a mechanical stress in direction $p$ and an induced electric field in direction $i$, the open-circuit voltage of a piezoelectric device can be written as follows:

$$
V=T_{p} g_{i p}
$$

Assuming that the voltage coefficient $g_{i p}$ is constant with the stress, and where $l$ is the gap between the electrodes.

\section{Materials}

Each piezoelectric material can be characterized with a set of parameters. For example, considering a stress $T_{p}$ as input, the strain coefficient $d_{i p}$ gives the relationship between the applied stress and the electric induction $D_{i}$ (therefore, current density is $J_{p}=\frac{d D}{d t}$ ), while the voltage coefficient $g_{i p}$ gives the voltage Equation (9). Thus, a high energy density piezoelectric material is characterized by a large product of the strain coefficient $\left(d_{i p}\right)$ and the voltage constant $\left(g_{i p}\right)$ [29]. The coupling factor $k_{i q}$, combining the piezoelectric properties of the material with its mechanical and electrical properties, gives the converted energy and efficiency of the harvester, as remarked by Equations (4) and (5). The mechanical characteristics (Young's modulus) define the robustness and toughness of the device and also play an important role in defining piezoelectric coefficients, Equation (3), and coupling factor. Dielectric permittivity also plays a similar role in definitions. All these parameters (determined by the material) are crucial in designing a harvesting system, making in turn material selection a primary factor in piezoelectric harvesters.

Table 1 lists some of the most common piezoelectric materials, mainly piezoceramics (that are polarized ferroelectric ceramics [26]), such as PZT [30] and barium titanate [31]. Out of them, Anton and Sodano [32] and Shen and colleagues [33] report PVDF polymer and micro-fiber composites (MFC) as highly flexible materials. MFCs are composites that combine the energy density of piezoceramic materials with the flexibility of epoxy [34]. In [33], the authors compared PZT with PVDF and MFC, they showed that although PZT shows the highest power density, it is not well suited for high g-vibrations because of its lower yield strength that results in lower robustness, leading to fracture. Furthermore, zinc-oxide $(\mathrm{ZnO})$ is an interesting material that is pushing the piezoelectric field to a nanometric scale. It is used to grow one dimensional hair-like nanowires, with diameters in the sub-one hundred nanometer scale and lengths ranging from several hundreds of nanometers to a few centimeters. Zinc exhibits both semiconductor and piezoelectric properties, it is relatively biosafe and biocompatible, so it can be involved in biomedical applications with little toxicity [35]. In [36] a strain coefficient of $\sim 10 \mathrm{pC} / \mathrm{N}$ was reported for zinc oxide nanowires.

The piezoelectric properties change logarithmically with age allowing them to stabilize. Therefore, manufacturers usually specify the constants of the material after a period of time [21,37]. Table 1 compares a set of piezoelectric materials based on the coefficients related to mechanical input and electrical output. 
Table 1. Coefficients for common piezoelectric materials [21,37-42]. Ceramic B is a modified barium titanate with improved stability and lower aging. Last two rows report strongly different values for two PMN-PT crystals; notice that this is not due to the slightly different stoichiometric composition but to the crystallographic cut (not reported in the table).

\begin{tabular}{|c|c|c|c|c|c|c|c|}
\hline \multirow{2}{*}{ Compound } & $d_{33}$ & $d_{31}$ & $d_{15}$ & $g_{33}$ & $g_{31}$ & $g_{15}$ & \multirow{2}{*}{ Curie Point $\left[{ }^{\circ} \mathrm{C}\right]$} \\
\hline & \multicolumn{3}{|c|}{$\left[10^{-12} \mathrm{C} \mathrm{N}^{-1}\right]$} & \multicolumn{3}{|c|}{$\left[10^{-3} \mathrm{~V} \mathrm{~m} \mathrm{~N}^{-1}\right]$} & \\
\hline PZT-2 & 152 & -60.2 & 440 & 38.1 & -15.1 & 50.3 & 370 \\
\hline PZT-4 & 289 & -123 & 496 & 26.1 & -11.1 & 39.4 & 328 \\
\hline PZT-5A & 374 & -171 & 584 & 24.8 & -11.4 & 38.2 & 365 \\
\hline PZT-5H & 593 & -274 & 741 & 19.7 & -9.1 & 26.8 & 193 \\
\hline PZT-8 & 225 & -37 & 330 & 25.4 & -10.9 & 28.9 & 300 \\
\hline Pz21 & 640 & -259 & 616 & 15.6 & -7.4 & 26.8 & 218 \\
\hline Pz23 & 328 & -128 & 421 & 24.7 & -9.6 & 34.3 & 350 \\
\hline Pz24 & 149 & -58 & 247 & 39.7 & -15.4 & 37.7 & 330 \\
\hline Pz26 & 328 & -128 & 327 & 28 & -10.9 & 38.9 & 330 \\
\hline Pz27 & 425 & -170 & 506 & 26.7 & -10.7 & 37.3 & 350 \\
\hline Pz28 & 275 & -114 & 403 & 31.4 & -13 & 37.3 & 330 \\
\hline Pz29 & 574 & -243 & 724 & 22.6 & -9.6 & 32.1 & 235 \\
\hline Pz34 & 46 & -5.33 & 43.3 & 25 & -2.9 & 27.9 & 400 \\
\hline Ceramic B & 149 & -58 & 242 & 14.1 & -5.5 & 21 & 115 \\
\hline $\mathrm{BaTiO}_{3}$ & 145 & -58 & 245 & 13.1 & -5.2 & 20.5 & 120 \\
\hline PVDF & -33 & 23 & - & 330 & 216 & - & 100 \\
\hline 0.70PMN-0.30PT & 1,611 & $-2,517$ & 157 & 29.2 & -45.6 & 9 & 150 \\
\hline 0.69PMN-0.31PT & - & - & 5,980 & - & - & 56 & 146 \\
\hline MFC M8528 & 460 & -210 & - & - & - & - & 80 \\
\hline
\end{tabular}

\section{Resonant Devices}

Piezoelectric transducers are frequently used in inertial generators. These systems are composed of a fixed reference, which transmits vibrations to an inertial mass located on a mechanical moving part, when an external acceleration is applied. Piezoelectric materials provide transduction, exploiting the mechanical strain occurring in such devices.

Inertial generators can be described as a second order mass-spring-damper system [29,43-45], along with a piezoelectric element connected parallel to the damper [28] (Figure 6). The system is governed by the following equation of motion:

$$
m \ddot{z}_{m}(t)+b \dot{z}_{m}(t)+k z_{m}(t)=F(t)
$$

where $m, b$ and $k$ are seismic mass, total damping coefficient and spring stiffness respectively, while $F(t)$ is an external force applied onto the device. The damping coefficient $b$ comprises of both mechanical losses and coefficient based on energy conversion, which are $b_{p}$ and $b_{e}$, respectively. The total stiffness of spring accounts to the spring stiffness $\left(k_{\text {spring }}\right)$ and the piezoelectric stiffness $\left(k_{\text {piezo }}\right)$. This is a good approximation as long as the structure vibrates with little displacements and the mechanical behavior of motion remains linear. 
Figure 6. (a) Mass-spring-damper-piezo model and (b) its resonant behavior.

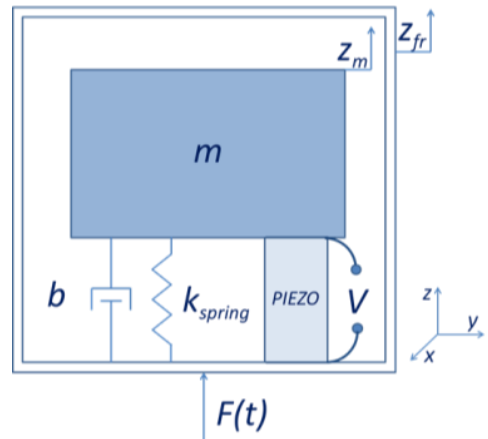

(a)

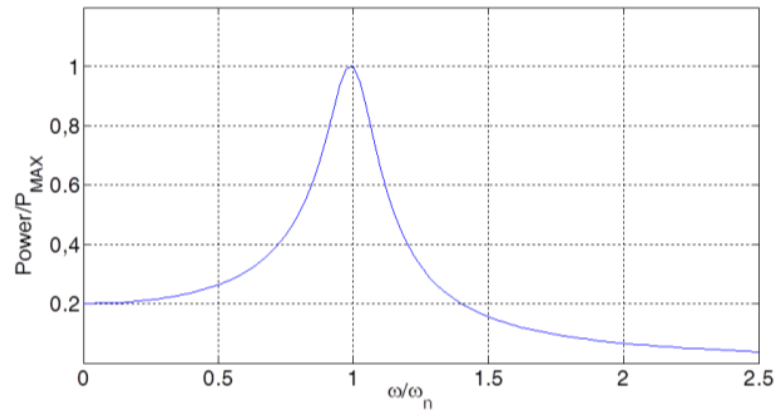

(b)

Such a system is characterized by a natural or resonant angular frequency $\left(\omega_{n}\right)$ given by:

$$
\omega_{n}=\sqrt{\frac{k}{m}}
$$

In practical cases $\omega_{n}$ has to be designed to match the expected ambient excitation angular frequency $(\omega)$. When this happens, the maximum energy is extracted from the transducer (as shown in Figure 6).

The power that the transducer can extract while working at resonance can be derived solving (8) for $z_{m}$. The harvested power is obtained by formulating the portion of the power flowing through the damper related to the transducing mechanism [21,45]:

$$
P_{e}=\frac{m \zeta_{e} a^{2}}{4 \omega_{n}\left(\zeta_{p}+\zeta_{e}\right)^{2}}
$$

where, $a=\omega_{n}^{2} Z$ is the acceleration in the case of sinusoidal vibratory excitation. The displacement of the device is $z_{f r}(t)=Z \sin (\omega t)$. The mass is $m ; \zeta_{e}$ and $\zeta_{p}$ are the transducer and the mechanical damping ratio, respectively $\left(\zeta=b / 2 m \omega_{n}\right)$. A high mechanical damping would flatten out the power curve $P_{e}$. Power output reaches its maximum when the electrical damping is equal to the mechanical damping [20,46] (Figure 7). Resonant devices are discussed below, based on operating modes $\left(d_{31}, d_{33}, d_{15}\right)$.

Figure 7. Power of the piezoelectric generator as a function of the electrical damping ratio. The black dashed line is obtained from Equation (12) by imposing $\zeta_{p}=\zeta_{e}$. For a given mechanical damping, the maximum extracted power is achieved when the electrical damping equals the mechanical damping.

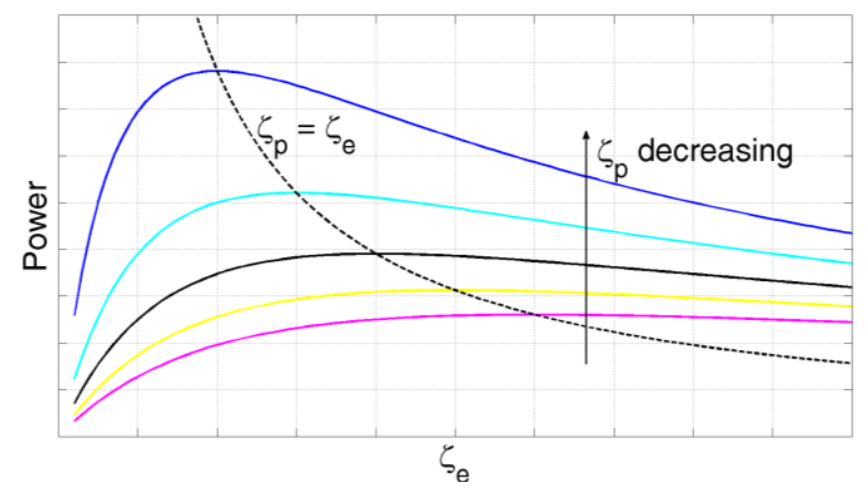




\section{1. $d_{31}$ Mode Generators}

In $d_{31}$ operating mode the material has an induced electric field in direction 3 , as a response to the stress along direction 1. Figure 8 shows the most common configuration of a piezoelectric harvester, which comprises of a rectangular beam, a tip mass and a piezoelectric material.

Figure 8. Rectangular cantilever beam $\left({ }^{\odot} 2005\right.$ IEEE. Reprinted with permission from [47]).

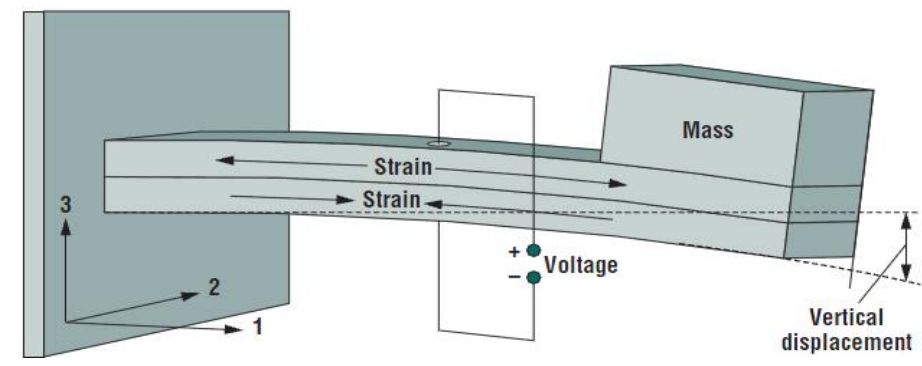

We can distinguish unimorph and bimorph configurations based on the piezoelectric material presence on top of the beam or on both sides. A thorough comparison of these two configurations was presented by $\mathrm{Ng}$ in [48]. The former was described as most suitable for lower frequencies and load resistance, whereas the latter showed optimal functioning at higher frequencies and higher loads, while being able to extract higher amount of power. Indeed, in bimorph cantilever the two piezoelectric pieces undergo opposite strain during operation, and they can be bonded electrically in series (to increase the voltage output) or in parallel (to increase the current output). Lu and colleagues [49] investigated the load resistance effort in case of bimorph cantilevers and pure resistive load. They formulated the following relationship for the optimal load:

$$
R_{o p t}=\frac{t}{W L \varepsilon_{33} \omega}=\frac{1}{C_{p} \omega}
$$

where, $t$ is the thickness, $L$ the length of the piezoelectric layer, $W$ the beam width, $\varepsilon_{33}$ the dielectric constant, $\omega$ the angular frequency and $C_{p}$ the parasitic capacitance of the piezoelectric material. This shows that the optimal resistance varies with geometrical configurations and material properties.

Wang and Song [35] developed a nanogenerator based on a zinc oxide nanowire array (Figure 9A). A silver paste was used as ground contact at the bottom of the nanowires, while the other electrodes were fabricated by means of a Pt film coated on the tip of an atomic force microscope (Figure 9C). Pt was chosen in order to form a Schottky barrier at the interface with $\mathrm{ZnO}$. The barrier allows the nanowire to accumulate charge during the deformation along its length (due to the piezoelectric effect) and discharging it on a load circuit only when the Schottky barrier is forward biased. This happens only during a small portion of the entire cycle, but resulting in a sharper and higher voltage (and power) output. The authors reported conversion efficiency ranging between $17 \%$ and $30 \%$, and a typical resonance frequency of $\sim 10 \mathrm{MHz}$. Each nanowire is estimated to provide with an output voltage of $\sim 8 \mathrm{mV}$ and corresponding power of $\sim 0.5 \mathrm{pW}$. Considering an array of 20 nanowires per $\mu \mathrm{m}^{2}$, the output power can be $\sim 10 \mathrm{pW} / \mu \mathrm{m}^{2}$. 
Figure 9. Nanowire array based generator presented by Wang and Song from [35] (Reprinted with permission from AAAS).

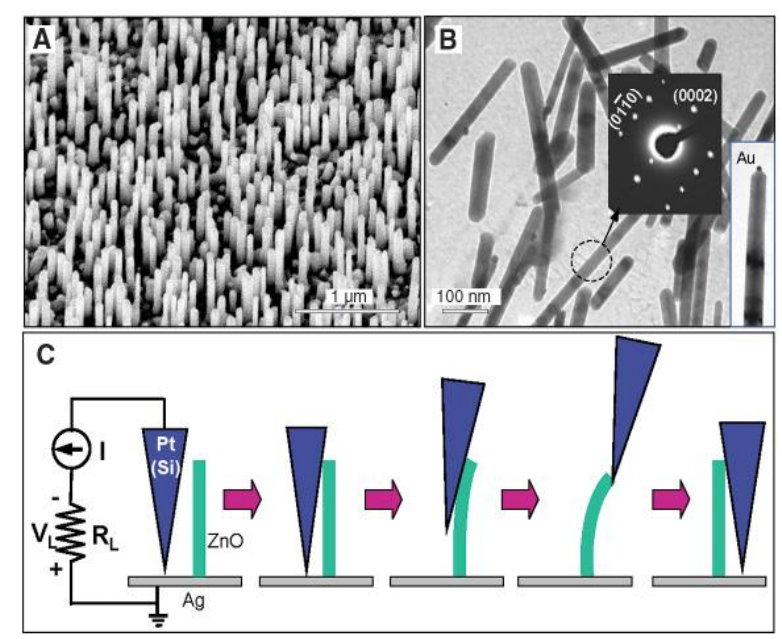

Figure 10. Design of a piezoelectric fine wire (PFW) generator on a flexible substrate [50] (Reprinted with permission from Macmillan Publishers Ltd.).

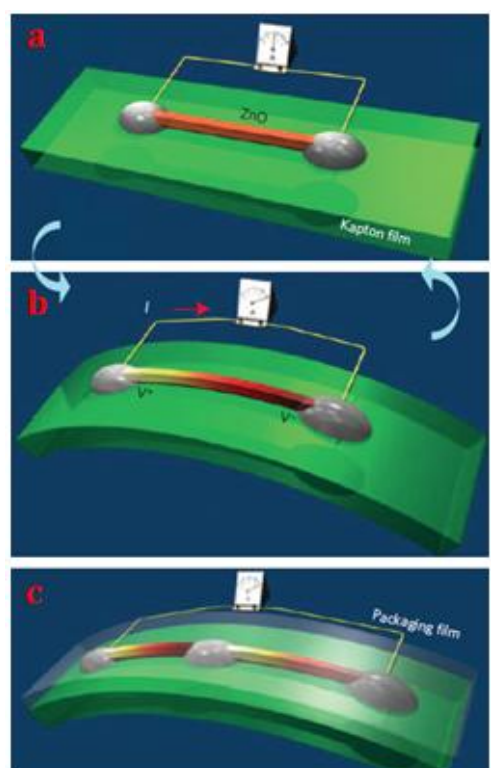

Vertically aligned piezoelectric nanowires may lack in mechanical robustness, lifetime, environmental adaptability and output stability. To overcome such inconveniences, a flexible power generator based on cyclic stretching-releasing mechanism for piezoelectric fine wires was proposed by Yang and colleagues [50]. In this work, a piezoelectric fine wire (PFW) lies flat on a flexible substrate with fixed ends onto the electrodes (Figure 10a). When the substrate is subjected to load, it bends (Figure 10b) inducing a tensile strain of $0.05 \%-0.1 \%$ in the wire. This leads to a drop in the piezoelectric potential along the wire, forcing electrons to flow along an external circuit to charge the wire. When the substrate is released, electrons flow back in the opposite direction. Periodically bending and releasing the PFW therefore generates an alternating current. Generators based on multiple PFWs can be integrated to raise the output voltage. 


\section{2. $d_{33}$ Mode Generators}

In $d_{33}$ operating mode the material is subjected to a stress in the same direction of the produced electric field. This operating mode led initially to impact harvesters [51-55], while vibrating generators were made only via $d_{31}$ effect. However, several researchers focused on fabricating vibrating devices with alternative modes to $d_{31}$. This research line is motivated by the fact that piezoelectric coefficients in $d_{33}$ and $d_{15}$ modes are higher than $d_{31}$ ones (Table 1), so this can possibly lead to devices with higher output power. $d_{33}$ vibrating generators can be used, for example, in industrial fields such as automotive and machinery or wherever there are mechanical joints that, due to tolerances, show relative movements between structural components. The cyclical movement of structures, due for example to the effect induced by the vibrational dynamics of the system, can be exploited by adopting appropriate mechatronic systems. Thanks to their geometry and to their structure, the mechanism is able to convert macroscopic displacement (in the order of millimeters) into a high force microscopic motion acceptable by the piezoelectric material.

As an example, a possible application of $d_{33}$ generators is represented by the car door latch system shown in Figure 11a. This assembly shows a cyclic displacement (highest value $\sim 1 \mathrm{~mm}$ ) with frequency range between 0 and $10 \mathrm{~Hz}$. In this view, it is possible to design an electromechanical $d_{33}$ system with a metal frame, to be coupled with the internal part of the closure, able to scale the displacement in values compatible with piezostacks (Figure 11b).

Figure 11. (a) Car door latch system; (b) a possible architecture of the harvester.

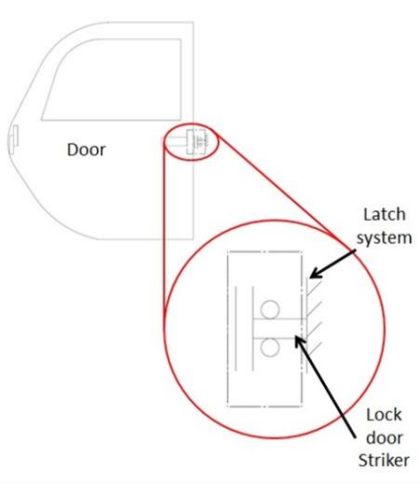

(a)

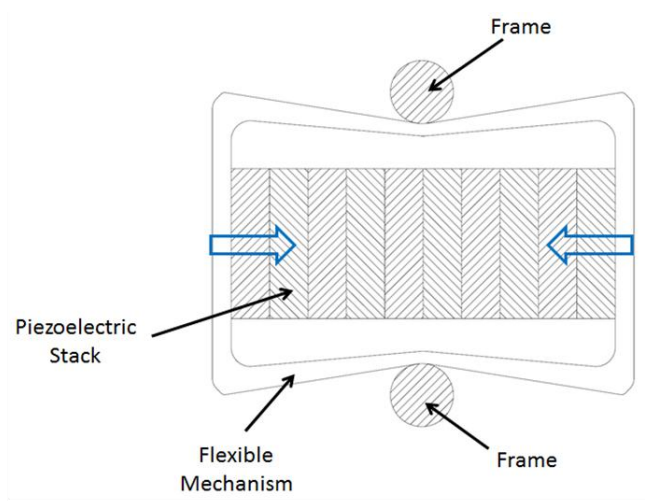

(b)

Figure 12. Comparison between (a) Interdigitated electrode (IDE) and (b) Top and bottom electrode (TBE) configurations $\left({ }^{\odot} 2012\right.$ IEEE. Reprinted with permission from [56]).

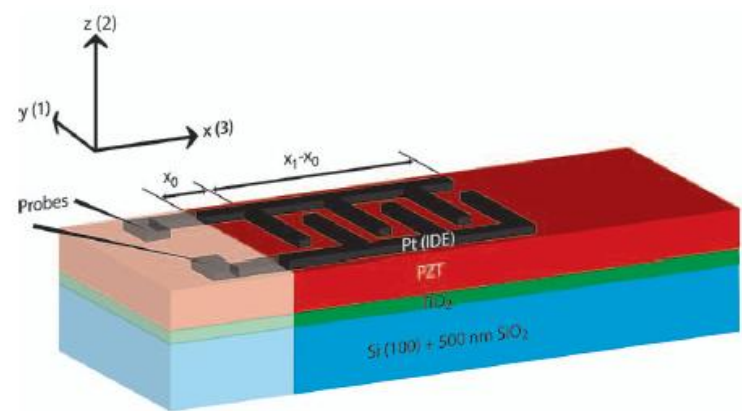

(a)

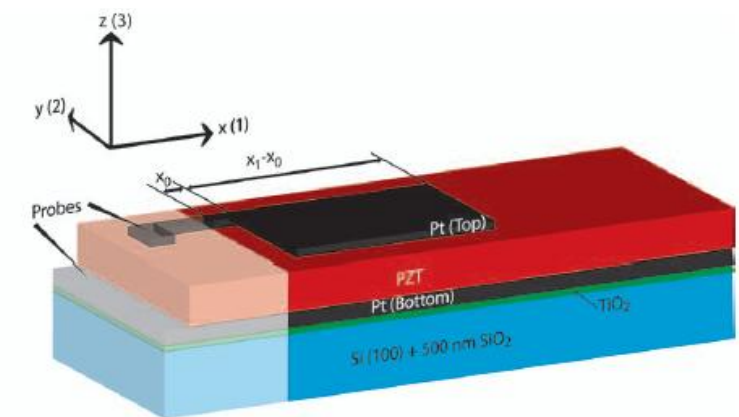

(b) 
Figure 13. Polarization with $d_{31}$ mode (a) and $d_{33}$ mode (b) piezoelectric harvesters ( 2013 IEEE. Reprinted with permission from [57]).

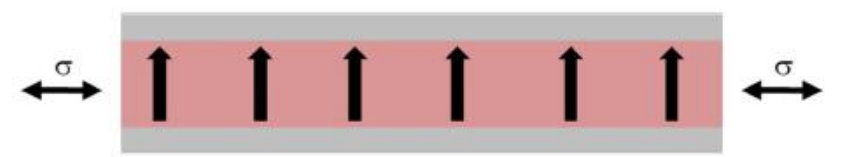

(a)

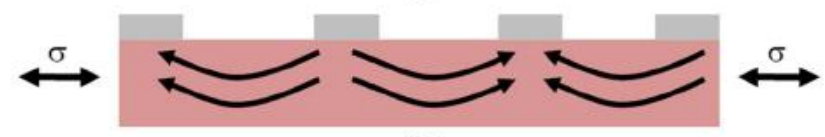

(b)

Electrode

Piezoelectric layer

Several $d_{33}$ operating modes were implemented with vibrating harvesters by using an interdigitated electrode patterning (IDE) instead of the top and bottom electrode (TBE) or parallel plate electrode (PPE) configurations of the $d_{31}$ devices (Figure 12). In this way the $d_{33}$ mode is obtained by letting the direction-3 to coincide to the length direction of the beam (Figure 13).

Typically a $d_{33}$ mode harvester develops a greater output voltage than $d_{31}$ devices because of its greater voltage coefficient $\left(g_{33}>g_{31}\right)$, and large gap between the electrodes. In $d_{33}$ generators the limiting factor is the length of the piezoelectric material instead of its thickness, hence the gap between electrodes can be made larger than that of $d_{31}$ devices. However, it is important to notice that greater electrode spacing requires higher voltage in order to polarize the piezoelectric material.

Furthermore, as it can be seen from Figure 13, the interdigitated configuration does not permit the efficient polarization of the material, resulting in curved polarization arrows. Therefore, non-polarization occurs along direction-3, whereas polarization follows in direction-1 just below the electrodes. This type of inefficiency leads to poor performance, in terms of output power.

Several research papers were published, attempting to analyze and unravel the problem of inefficient polarization [58-60]. In particular, Knight and colleagues [60] came up with finite element analysis resulting in a 0.8 optimal ratio between the width of each electrode fingers and the thickness of piezoelectric material, while the ratio between width of the cantilever beam and the finger spacing should be as large as possible. $d_{33}$ and $d_{31}$ unimorph configurations were also compared in terms of charge generated, by introducing a parameter that accounts for the percentage of the 3-direction polarized material $\left(\% d_{33}\right)$. They concluded that, since $d_{33}$ coefficient is roughly two times $d_{31}, \% d_{33}$ should be at least 50\%, otherwise the IDE configuration has lower efficiency than the TBE one.

To date several IDE devices have been presented [57,61-66]. Jeon and colleagues developed an IDE micropower generator [61,62]. It employed an interdigitated Ti/Pt electrode patterned on top of PZT, its dimensions were submillimetric and it was able to harvest about $1 \mu \mathrm{W}$ power $\left(2.4 \mathrm{~V}_{\mathrm{dc}}\right.$ after a rectifying stage) at a resonance frequency of $13.9 \mathrm{kHz}$. Furthermore, a new topology of serpentine cantilever [62] was proposed in order to increase the length of the device maintaining a limited size, but no prototypes were fabricated.

In 2010, Park and colleagues [63] fabricated and compared two millimetric piezoelectric harvesters involving $d_{33}$ and a $d_{31}$ modes, with same dimensions and resonant frequency. Later, the same group compared two submillimetric $d_{33}$ and a $d_{31}$ harvesters [57,64], after an experimental optimization of the $d_{33}$ device by fabricating a set of twelve different versions of the $d_{33}$ cantilever with different 
finger width and finger spacing. In both works higher output power was obtained with the $d_{31}$ harvester and higher output voltage with the $d_{33}$ device $[57,63,64]$.

An innovative energy harvester was presented by Zhou and colleagues based on self-biased magneto-electric response [67,68], combining magnetic and piezoelectric vibrational energy harvesting. The device consists of a piezoelectric Macro-Fiber Composite (MFC, M-4010-P1, Smart Material Corp., Sarasota, FL, USA) bonded onto a magnetostrictive Ni cantilever. This device has three different operating modes (see Figure 1 for classification), mechanical electromagnetic, piezoelectric and hybrid respectively. In pure piezoelectric mode, the device harvests $168 \mu \mathrm{W}$ on a $4 \mathrm{M} \Omega$ load, for a mechanical vibration of $0.17 \mathrm{~g}$ at $22.5 \mathrm{~Hz}$ frequency.

Delnavaz and Voix [69] studied the possibility of harvesting energy from ear canal dynamic motion and designed two micro-power generators, one of which is piezoelectric based. It consists of a flexible sheet of PVDF (provided by Measurement Specialties, [70]), so that the device is biocompatible [69,71]. The device is fabricated by cutting a $\mathrm{T}$-shape from the piezo sheet, joining the tips of the $\mathrm{T}$ cross and letting the stem of the $\mathrm{T}$ as a tail, thus forming a ring-like device. This structure is mounted in a headset and has to be placed inside the ear canal. During mouth movements the piezo-ring will be deformed, therefore generating an electrical output.

In 2010, Qi and colleagues [72] proposed an innovative method to integrate a high efficiency piezoelectric material onto flexible materials. The method consists of printing PZT ribbons with a thickness of few hundreds nanometers, onto a PDMS substrate. It allowed achieving high piezoelectric coefficients with the advantage of flexibility. The same group also presented a flexible and stretchable device from buckled PZT ribbons, showing the possibility to integrate the high performance $d_{33}$ PZT with a stretchable device [73].

More recently, Dagdeviren and colleagues [16] employed PZT ribbons in a system able to scavenge energy from movements of heart, lung and diaphragm. The harvester was arranged onto a flexible membrane, which integrates also a rechargeable battery and a bridge rectifier. The whole system was encapsulated with biocompatible layers (polyimide) and the absence of toxicity was examined with rat smooth muscle cells. The system power generation capability was in vivo tested on bovine and ovine hearts. Results showed that a stack of five PZT sheets was able to harvest up to $1.2 \mu \mathrm{W} / \mathrm{cm}^{2}$, sufficient to operate a cardiac pacemaker. Such a system can avoid risks of surgical procedures to replace the depleted batteries of implantable devices, as pacemaker, neural stimulators, cardioverter defribillators and so on.

\section{3. $d_{15}$ Mode Generators}

$d_{15}$ operating mode characterizes shear stress harvesters. In this mode the piezoelectric material is polarized along direction 1 and is subjected to a shear stress $\sigma_{31}$. The electrical output is perpendicular to both the polarization and the applied stress. The main problem of these devices is related to the perpendicularity of the polarization direction and the electrical output (Figure 14), which constrains to use a set of electrodes for the polarization and a different set of electrodes for operation.

Ren and colleagues [74] proposed a non-resonant shear stress harvester involving PMN-PT crystal (last row of Table 1). It comprises two piezoelectric wafers polarized along their length, sandwiched between three aluminum blocks. One block is left free to vibrate with external oscillations (Figure 15). 
The two piezoelectric wafers were connected in series, with different mass load bonded to the central aluminum block. Under a brass load mass of $200 \mathrm{~g}$ and a corresponding acceleration of $121.6 \mathrm{~m} / \mathrm{s}^{2}$ at $500 \mathrm{~Hz}$ frequency, the device delivered $11.3 \mathrm{~V}$ and $0.7 \mathrm{~mW}$ on a resistive load of $91 \mathrm{k} \Omega$.

Figure 14. Shear stress harvester $\left(d_{15}\right.$ operating mode).

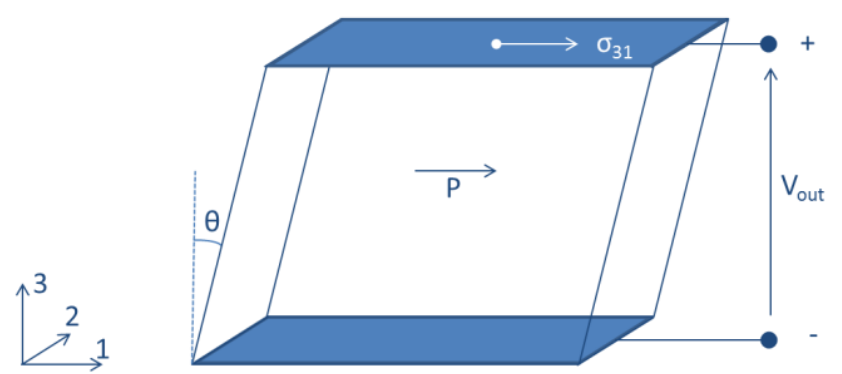

Figure 15. Nonresonant $d_{15}$ device presented by Ren and colleagues $\left({ }^{\odot} 2010\right.$ IEEE. Reprinted with permission from [74]).

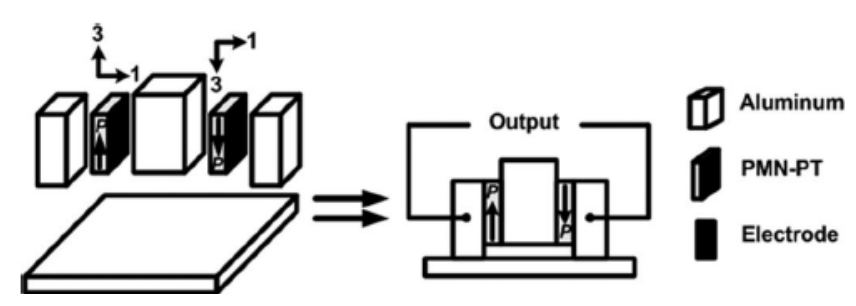

Figure 16. $\mathrm{ZnO}$ nanoribbons array presented by Majidi et al. [75] $\left(^{\odot}\right.$ IOP Publishing. Reproduced with permission of IOP Publishing).

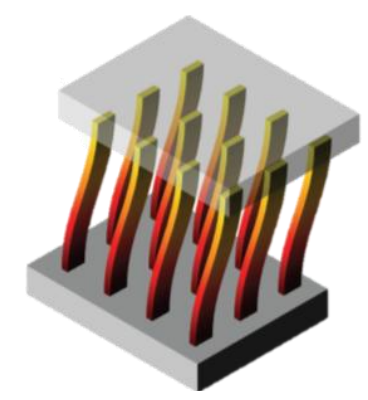

Majidi and colleagues [75] designed a shear-mode $\mathrm{ZnO}$ harvester that does not need a nanostructured cathode and allows a permanent bonding of electrodes to the ribbons (Figure 16). The nanoribbons are polarized along their thickness, so that a sliding movement of the electrodes induces voltage drop along the length of nanoribbons. The model developed by the authors predicted that such a system could harvest up to $100 \mathrm{nW} / \mathrm{mm}^{3}$.

Wang and Liu [76] developed a piezoelectric energy harvester for pressurized water flow. They employed a PZT-5H in $d_{15}$ mode onto a nickel flexible diaphragm that vibrates when the pressure of flow changes. Their device achieved $0.45 \mathrm{nW}$ on a matched load of $1.6 \mathrm{M} \Omega$ for a pressure amplitude of $20.8 \mathrm{kPa}$ at $45 \mathrm{~Hz}$ frequency.

Zhao and colleagues [77] fabricated a piezoelectric harvester with two $d_{15}$ PZT-51 connected in series, as shown in Figure 17. They also compared its performances with those of a $d_{15}$ single element and demonstrated the higher performances with the series topology. 
Figure 17. Schematic representation and picture of the $d_{15}$ series connected harvester of Zhao and colleagues [77] $\left({ }^{\odot}\right.$ IOP Publishing. Reproduced by permission of IOP Publishing).
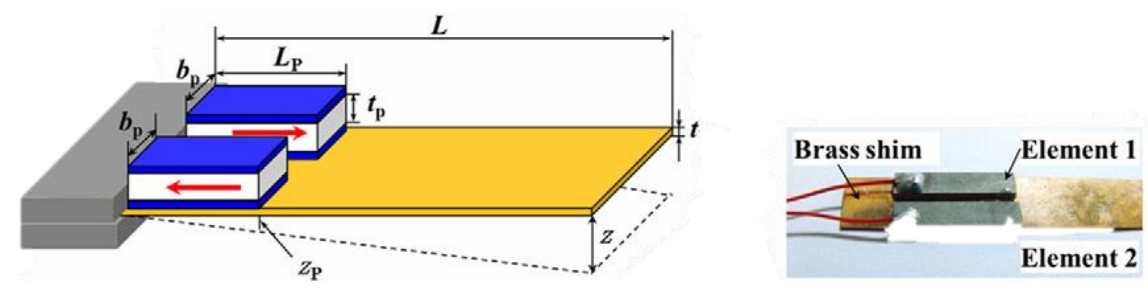

\subsection{Comparison among Modes}

Resonant piezoelectric generators are the easiest solution for motion harvesting [21]. They can be shaped in simple geometrical configurations by involving a $d_{31}$ piezoelectric element. However, different sophisticated solutions were developed in order to increase the extracted power ( $d_{15}$ devices) or output voltage ( $d_{33}$ devices) and to scale the technology [35,50,75].

Table 2 summarizes the reviewed literature, by collectively comparing significant parameters for each device to evaluate the power factor, that is defined as the output power normalized with respect to the device volume and input acceleration $(g)$.

Table 2. Resonant devices comparison. The last column reports the power factor, i.e., the output power density normalized with the input acceleration (expressed in $g=9.81 \mathrm{~m} / \mathrm{s}^{2}$ ).

\begin{tabular}{|c|c|c|c|c|c|c|c|c|c|c|}
\hline \multirow{2}{*}{ Reference } & \multicolumn{2}{|c|}{ Material } & \multirow{2}{*}{$\begin{array}{c}\mathbf{d}_{\mathrm{ij}} \\
{[\mathrm{pm} / \mathrm{V}]}\end{array}$} & \multirow{2}{*}{$\begin{array}{r}\mathbf{V}_{\text {device }} \\
{\left[\mathbf{m m}^{3}\right]} \\
\end{array}$} & \multirow{2}{*}{$\begin{array}{c}\mathbf{V}_{\text {piezo }} \\
{\left[\mathrm{mm}^{3}\right]} \\
\end{array}$} & \multirow{2}{*}{$\begin{array}{c}\mathbf{f}_{\mathrm{n}} \\
{[\mathrm{Hz}]}\end{array}$} & \multirow{2}{*}{$\begin{array}{l}\mathbf{R}_{\mathbf{L}} \\
{[\Omega]}\end{array}$} & \multirow{2}{*}{$\begin{array}{c}\mathbf{V}_{\text {OUT }} \\
{[\mathrm{V}]}\end{array}$} & \multirow{2}{*}{$\begin{array}{c}\mathbf{P}_{\text {density }} \\
{\left[\mathrm{W} / \mathrm{cm}^{3}\right]}\end{array}$} & \multirow{2}{*}{$\begin{array}{c}\text { Power Factor } \\
{\left[\mathrm{W} /\left(\mathrm{g}^{2} \mathbf{c m}^{3}\right)\right]}\end{array}$} \\
\hline & Name & Mode & & & & & & & & \\
\hline [78] & AlN & $\mathrm{d}_{31}$ & - & 0.5 & 0.0004 & $1.4 \times 10^{3}$ & $650 \times 10^{3}$ & 1.6 & $4 \times 10^{-3}$ & $248 \times 10^{-6}$ \\
\hline [48] & $\mathrm{PZT}$ & $d_{31}$ & 320 & 212.5 & 80.4 & 223.8 & $9.9 \times 10^{3}$ & - & $77 \times 10^{-6}$ & $1.4 \times 10^{-6}$ \\
\hline$[61]$ & $\mathrm{PZT}$ & $\mathrm{d}_{33}$ & - & - & 0.00002 & $13.9 \times 10^{3}$ & $5.2 \times 10^{6}$ & $2.4 \mathrm{dc}$ & - & - \\
\hline \multirow{2}{*}[63]{} & $\mathrm{PZT}$ & $\mathrm{d}_{33}$ & 100 & 3.5 & 0.014 & 118.1 & $4.5 \times 10^{6}$ & 4.7 & $136 \times 10^{-6}$ & $543 \times 10^{-6}$ \\
\hline & $\mathrm{PZT}$ & $d_{31}$ & -55 & 3.5 & 0.014 & 130.8 & $11 \times 10^{3}$ & 0.77 & $1.9 \times 10^{-3}$ & $7.8 \times 10^{-3}$ \\
\hline \multirow{2}{*}{ [57] } & $\mathrm{PZT}$ & $d_{33}$ & 100 & 1.1 & 0.003 & 243 & $2 \times 10^{6}$ & $2 \mathrm{rms}$ & $1.6 \times 10^{-3}$ & $6.4 \times 10^{-3}$ \\
\hline & $\mathrm{PZT}$ & $\mathrm{d}_{31}$ & -55 & 1.1 & 0.003 & 243 & $9.9 \times 10^{3}$ & $1.5 \mathrm{rms}$ & $2 \times 10^{-3}$ & $8.1 \times 10^{-3}$ \\
\hline [77] & PZT & $\mathrm{d}_{15}$ & 700 & 171.2 & 65 & 73 & $2.2 \times 10^{6}$ & 6.2 & $51 \times 10^{-6}$ & - \\
\hline [76] & $\mathrm{PZT}$ & $d_{15}$ & 741 & 4.8 & 2.5 & 45 & $1.6 \times 10^{6}$ & $19 \times 10^{-3} \mathrm{rms}$ & $87 \times 10^{-6}$ & $67.8 \times 10^{-3}$ \\
\hline [74] & PMN-PT & $\mathrm{d}_{15}$ & 3,080 & 24,100 & 156 & - & $91 \times 10^{3}$ & 11.3 & $29 \times 10^{-6}$ & $189 \times 10^{-9}$ \\
\hline [35] & $\mathrm{ZnO}$ & $d_{31}$ & 10 & - & 9.7 & $10 \times 10^{6}$ & $500 \times 10^{6}$ & $8 \times 10^{-3}$ & $4 \times 10^{-6}$ & $624 \times 10^{-15}$ \\
\hline [68] & MFC & $d_{33}$ & 400 & 340 & 120 & 22.5 & $4 \times 10^{6}$ & - & $494 \times 10^{-6}$ & $17.1 \times 10^{-3}$ \\
\hline [69] & PVDF & $\mathrm{d}_{33}$ & 33 & 549.5 & 24.2 & 1.5 & $10 \times 10^{6}$ & - & $364 \times 10^{-6}$ & - \\
\hline
\end{tabular}

Based on the analysis of various configurations in the reviewed literature, we can point out that $d_{31}$ represents the most used operating mode for piezoelectric-based devices. $d_{33}$ vibratory scavengers were fabricated in the attempt to overcome $d_{31}$ constraints with power performance. Despite the expectations $d_{33}$ devices do not show effective performances, because of polarization issues (Figure 13) due to a percentage of piezoelectric material that does not contribute to energy transduction. However, design optimizations were proposed through finite element simulations [60], but to our knowledge no device was fabricated following such guidelines. As reported in Table 2, $d_{33}$ harvesters offer higher 
voltage output in comparison to $d_{31}$ devices. On the other hand, $d_{15}$ mode appears to show the best power performances but it requires a complex fabrication process.

From the perspective of employed materials, PZT has been widely used. However, PMN-PT shows higher piezoelectric coefficients with respect to PZT, while $\mathrm{ZnO}$ is allowing a rapid growth in nano-scale harvesting technologies. Furthermore, recent studies report high power densities $\left(2.7 \mathrm{mWcm}^{-3}\right.$ in [79]) for $\mathrm{ZnO}$ nanowire arrays, that are being used for novel applications such as the detection of facial wrinkling with help of $\mathrm{ZnO}$ nanowire-based super-flexible nanogenerator harvesters [80].

\section{Optimal Shapes}

Rectangular cantilever beams often suffer with over strain at grounded point (near clamping) of the oscillator. Therefore, alternative mechanical structures were investigated in order to prevent overstrain [7,47,81,82]. This goal was achieved by fabricating new possible shapes for cantilever beams, such as trapezoidal beam (Figure 18). These beams distribute the strain more evenly along the structure; they also allow loading the device with higher excitation, leading to duplicate the harvested energy density. Mateu and Moll [7] investigated triangular shaped cantilevers.

Figure 18. Trapezoidal beams $\left({ }^{\circledR} 2005\right.$ IEEE. Reprinted with permission from [47]).
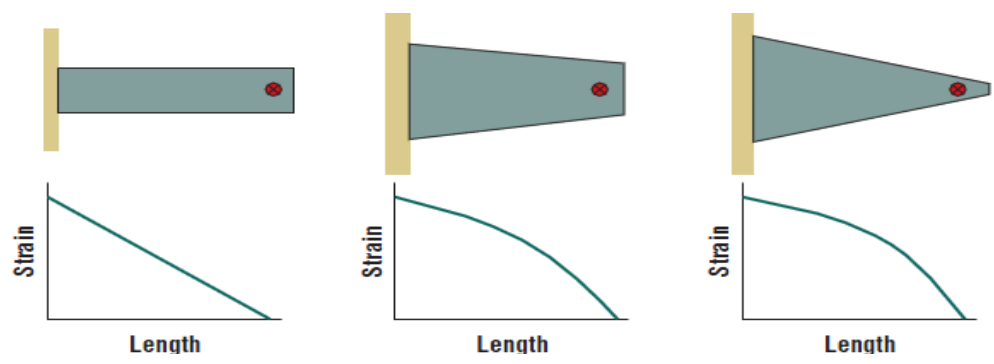

Marzencki and colleagues [78,83] developed a MEMS cantilever within the European VIBration Energy Scavenging (VIBES) project, using a deep reactive ion etching on a SOI wafer. They studied the possibility of introducing two angles of curvature at the beginning and at the end of the beam (before the mass) in order to reduce the overstrain [78,83].

\section{Frequency Tuning}

Resonant devices have limitations, as described above, because of their narrow bandwidth (approximately equal to $2 \zeta \omega_{n}$, [47], which typically means few hertz), so they can work efficiently only at their natural frequency (defined by geometry and materials). In this view, several solutions were explored in order to enlarge the bandwidth of the transducer [47,84-86]. Indeed this kind of systems can be used in many applications in which frequency range is wide, due to the environmental conditions. For example in the machinery field, structures are subjected to random, broad spectrum oscillations depending on their specific working principle but also on the wear of the surfaces cyclically in contact. Some passive tuning solutions, such as a moveable clamp that changes the beam length, or nonlinear, bistable structures with destabilizing axial loads are shown in Figure 19. 
Active tuning harvesters were discussed in [87-91]. Eichhorn and colleagues [88] developed an actuated harvester using PZT both for harvesting and actuation. It consists of a two beams device with three arms (Figure 20).

Figure 19. Cantilever with axial load. The right inset shows how the resonating frequency decreases as a function of axial loads. Moreover, the relationship is almost linear up to half the buckling load $\left({ }^{\odot} 2005\right.$ IEEE. Reprinted with permission from [47]).

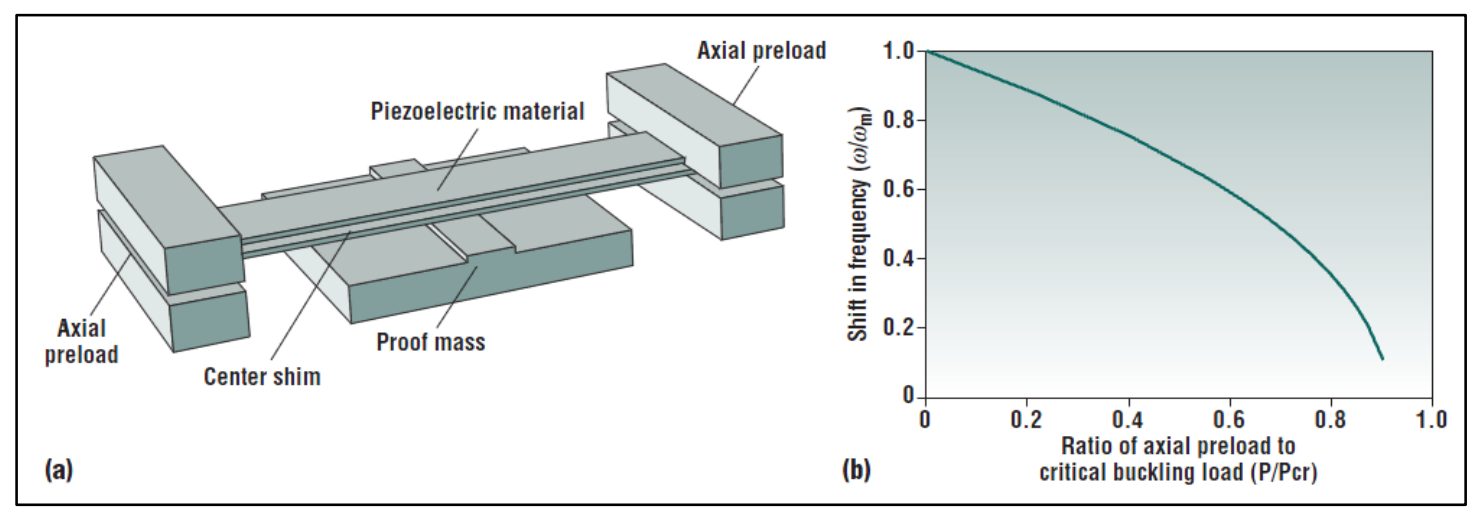

Figure 20. Self-tuning double cantilevered harvester [88] $\left({ }^{\odot}\right.$ IOP Publishing. Reproduced by permission of IOP Publishing).

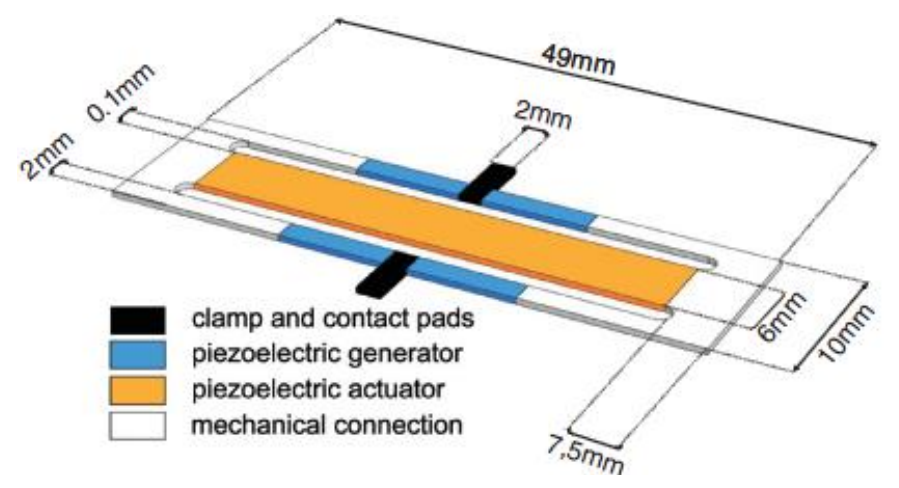

In such a device, the central and larger arm houses the actuator, whilst two harvesters are located in the lateral tight arms. The actuator was designed longer than the transducers, based on previous experimental findings [92]. The control unit mainly consists of a microcontroller, an acceleration sensor and a step-up converter for actuator voltage conditioning. The control unit is equipped with a look-up table in order to avoid a higher power dissipation due to a continued use of the embedded accelerometer. The accelerometer is OFF for most of the time and is turned ON periodically to give a feedback and in case update the look-up table (to overcome aging effects and temperature dependence). The authors reported that this device is capable to harvest up to $90 \mu \mathrm{W}$ at an acceleration amplitude of $0.6 \mathrm{~g}$. The natural frequency can be tuned within 150 and $215 \mathrm{~Hz}$ with actuator voltages between -30 and $+45 \mathrm{~V}$. Furthermore, the average consumption of the whole control unit is around $11 \mu \mathrm{W}$ if the system maintains a constant resonance frequency, however the power consumption can increase by several orders of magnitude if the ambient vibration shifts. Furthermore, it is important to note that the equipped dc-dc converter does not allow negative voltages, so the authors are working on an enhanced device with separated ground electrodes in order to overcome this issue. 
Another approach is to enlarge the bandwidth by fabricating an array of cantilevers with different natural frequencies $[43,93]$. Such device allows to convert energy from different sources at different frequencies, however it reduces the harvested power per unit area because only one cantilever of the array works efficiently for a given source (at a given frequency), while the others do not.

Roundy and colleagues proposed a similar device obtained connecting three spring-mass-damper systems with different natural frequencies [47]. The resulting device output is almost an overlap of the single subsystems response (Figure 21).

Figure 21. Multimass harvesting system $\left(^{\odot} 2005\right.$ IEEE. Reprinted with permission from [47]).

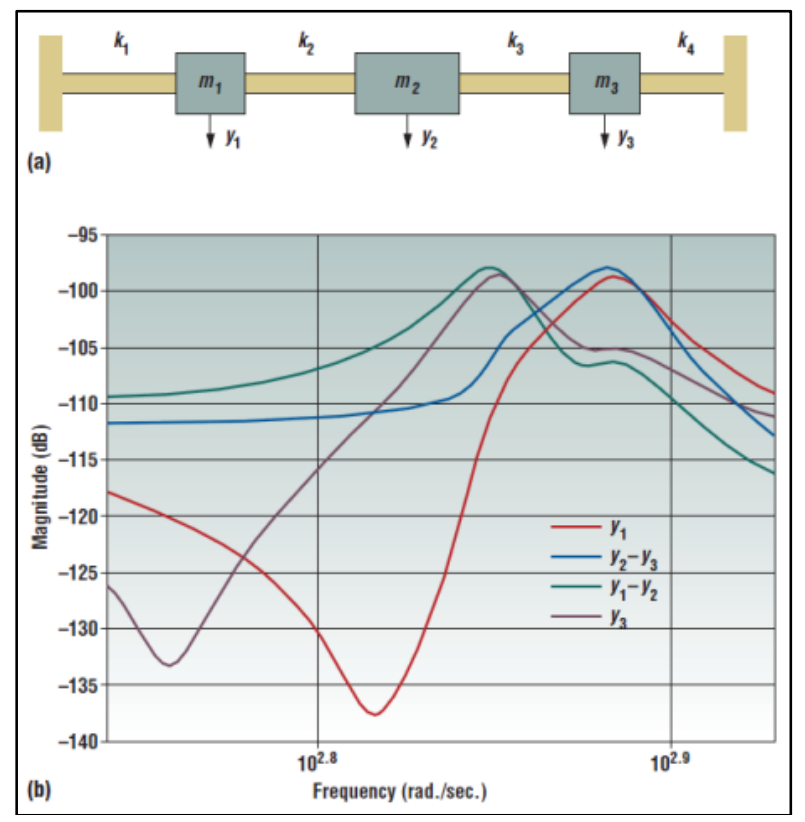

\section{Non-Resonant Devices}

A novel approach based on nonlinear oscillators was proposed by Cottone and colleagues [94]. The authors demonstrated that a bistable oscillator could widen the bandwidth of a traditional resonant system. The design of this device derives from the inverted pendulum; in which reaction forces from two permanent magnets are used (one on the tip mass of cantilever, and the other just in front on an adjustable stage) to provide two stable states.

Among all the proposed devices [95-100], Andò and colleagues [96] developed a MEMS harvester based on the bistable oscillator model (Figure 22).

Figure 22. MEMS nonlinear oscillator [96] $\left({ }^{\circledR}\right.$ IOP Publishing. Reproduced by permission of IOP Publishing).

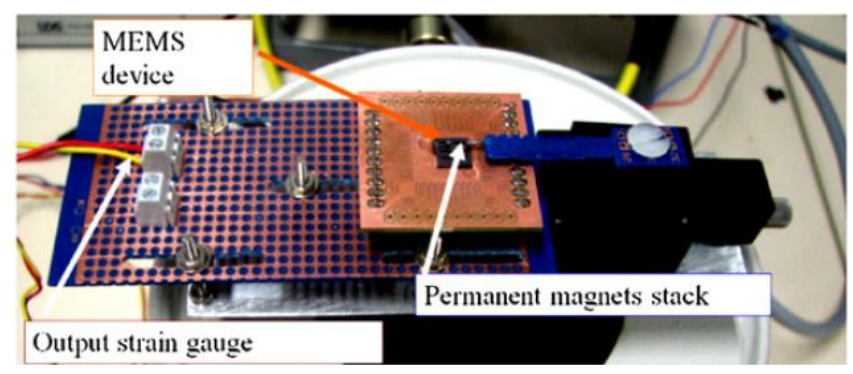


It can be referred to a mass-spring-damper system, similar to Equation (8), but with an additional nonlinear term described by a nonlinear potential energy function:

$$
m \ddot{z}+b \dot{z}+\Psi=f(t)
$$

where $m$ is the mass of beam, $b$ is the damping coefficient, $f(t)$ is the excitation force and $\Psi$ is a nonlinear term (which also includes the elastic constant $k$ ) [101]:

$$
\Psi \triangleq \frac{\partial U(z)}{\partial z}
$$

The potential energy function $U(z)$ can be chosen from a variety of equations [102,103]. Here, for simplicity, we report a standard quadratic equation:

$$
U(z)=-\alpha z^{2}+\beta z^{4}
$$

where $\alpha$ and $\beta$ are two parameters that allow determining the potential shape. The bistable behavior is described by the potential energy Function (14), reported in the lower part of Figure 23b, which shows two wells representing the stable states.

Figure 23. Comparison between linear and nonlinear oscillator with respect to potential energy function [96] ( ${ }^{\odot}$ IOP Publishing. Reproduced by permission of IOP Publishing).

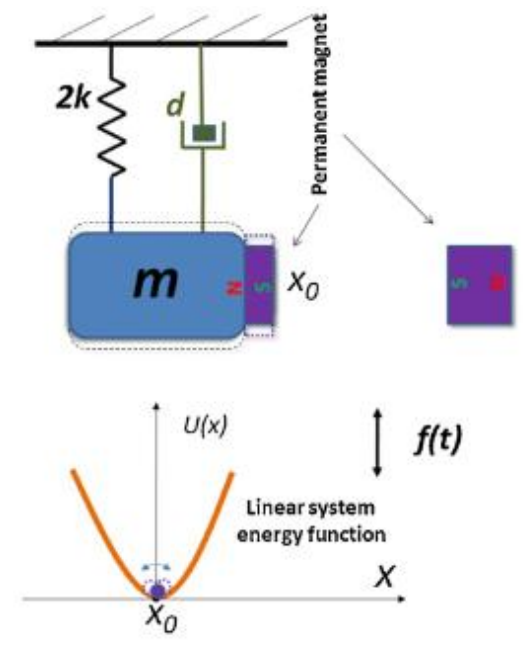

(a)

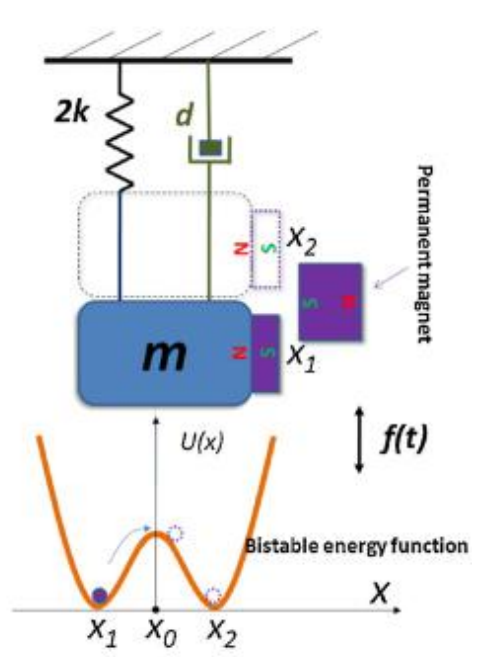

(b)

Calling $\Delta$ the distance between magnets (Figure 24), three cases can be described:

- Large value of $\Delta$ : magnetic force is negligible and the cantilever behavior is linear, such as resonant devices. These refer to the model reported in Figure 23a;

- Small value of $\Delta$ : the external magnet is close to the cantilever tip, which is confined in one of the two stable states along the $z$ axis of Figure 24. The system cannot switch between the two stable states due to the high commutation potential $U_{0}$. In this case, the oscillation is small and linear around one of the two stable states.

- Medium value of $\Delta$ : in a particular range of $\Delta$ (depending on the vibration input) the system is able to commute between two stable states, which results in non-linear behavior of the device.

The fabricated MEMS device operated in the latter condition (nonlinear oscillation). Experimental tests resulted in the displacement spectrum (for the tip) shown in Figure 25, under an excitation input 
of Gaussian white noise with a standard deviation $\sigma=20 \mu \mathrm{N}$ (that corresponds to an acceleration of $7.7 \mathrm{~ms}^{-2}$ ), and a distance $\Delta \sim 1.7 \mathrm{~mm}$ between the magnets.

Figure 24. Nonlinear cantilever [96] $\left(^{\odot}\right.$ IOP Publishing. Reproduced by permission of IOP Publishing).
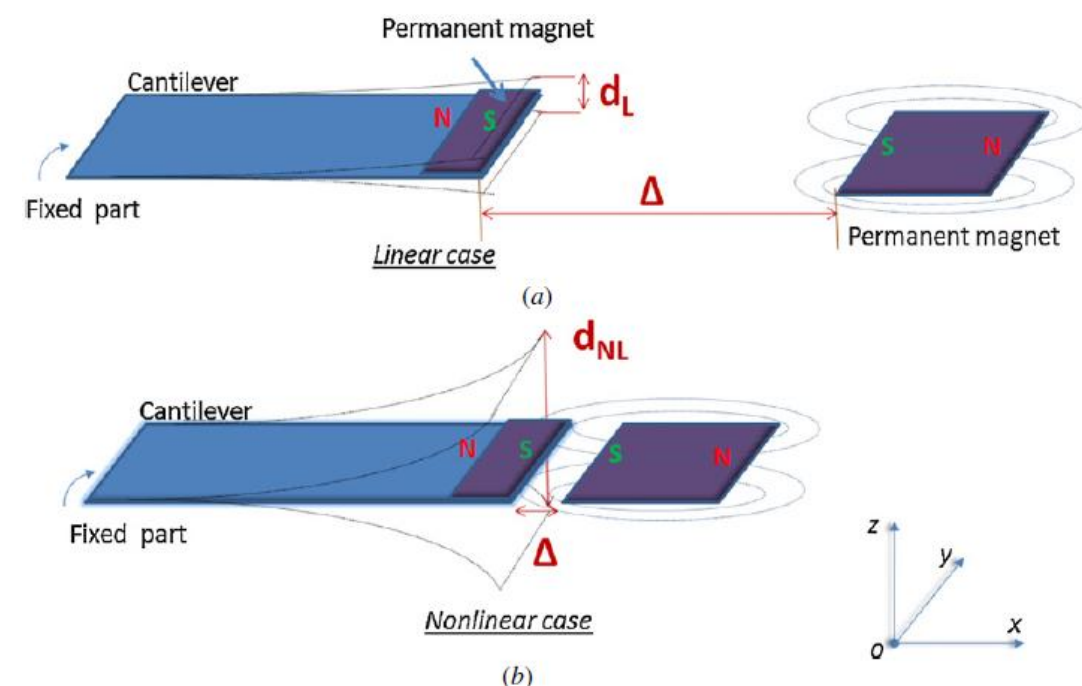

Figure 25. Displacement spectrum with $\sigma=20 \mu \mathrm{N}$ [96] $\left({ }^{\odot}\right.$ IOP Publishing. Reproduced by permission of IOP Publishing).

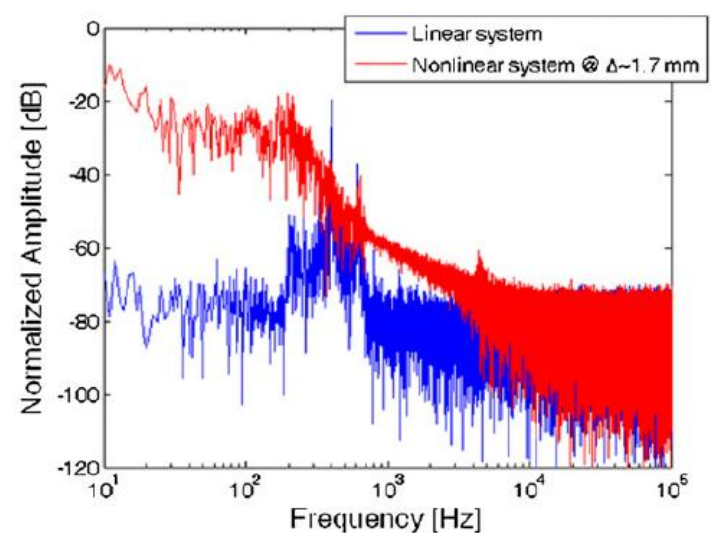

The bi-stable behavior was also achieved by involving two magnets with the same polarity of the cantilever magnetic tip [104,105]. These magnets are deployed not just in front of the tip, but shifted upwards and downwards within a frontal stage, to obtain an attraction between the magnetic tip and the two fixed magnets. Other research papers showed similar bistable systems where the switching between stable states is driven by internal signals [106,107].

Qiu and colleagues [108] demonstrated a bi-stable device consisting of a clamped-clamped buckled beam. $\mathrm{Xu}$ and colleagues [109] proposed a simply supported buckled beam, stating that this mechanism enhances the clamped-clamped transduction mechanism. Other bistable solutions based on buckled beam configuration were demonstrated by Arrieta and colleagues in [110] and by Cottone and colleagues in [111]. Buckled beams do not require permanent magnets and are therefore better suited for miniaturization. Andò and colleagues investigated new solutions to design bistable vibration harvesters in [112,113]. 
A bio-inspired device was proposed as well [114] (Figures 26 and 27). It is designed to mimic the auditory hair bundle structure. The auditory structure is responsible to stimulate the brain with electrical signals in response to the oscillations due to pressure forces of propagated sound. It mechanically amplifies the movements of the hair cells, thanks to a negative stiffness, which conveys a bi-stable behavior. The proposed device is composed by a four bar structure, linked by thin spring steel flexural joints. A piezoelectric cantilever can be placed on the coupler link.

Figure 26. Bio-inspired bi-stable structure [114] $\left(^{\odot}\right.$ IOP Publishing. Reproduced by permission of IOP Publishing).

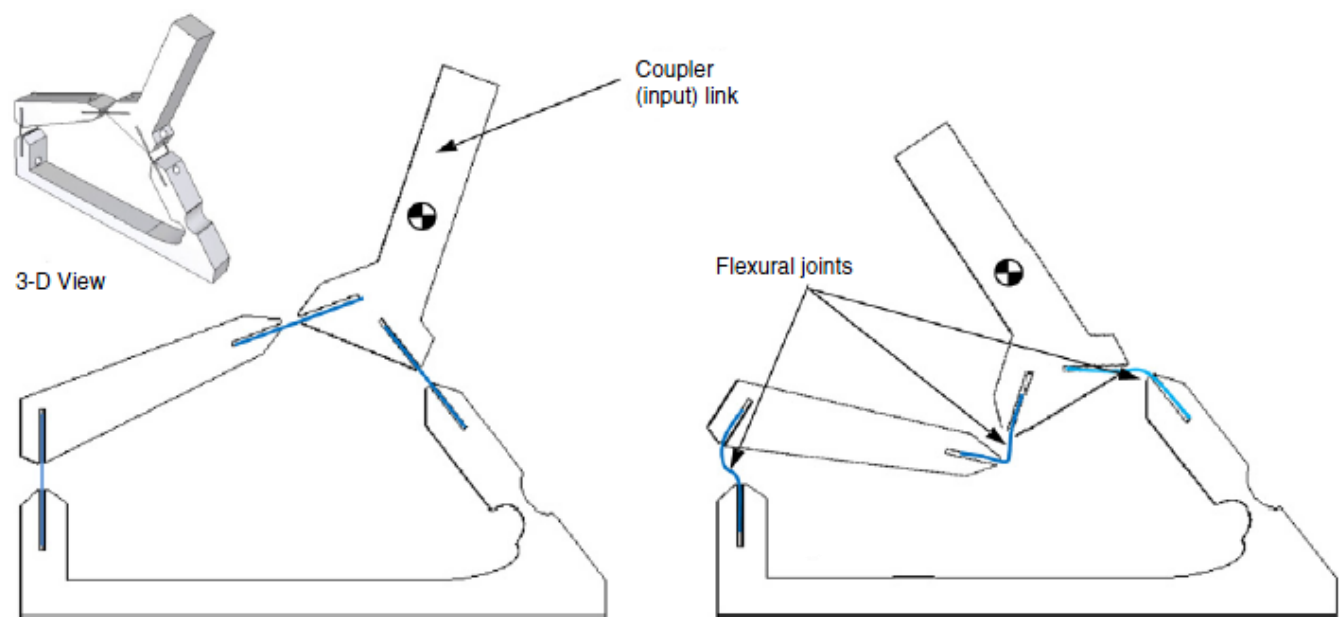

Figure 27. Experimental setup of the bio-inspired harvester [114] $\left(^{\odot}\right.$ IOP Publishing. Reproduced by permission of IOP Publishing).

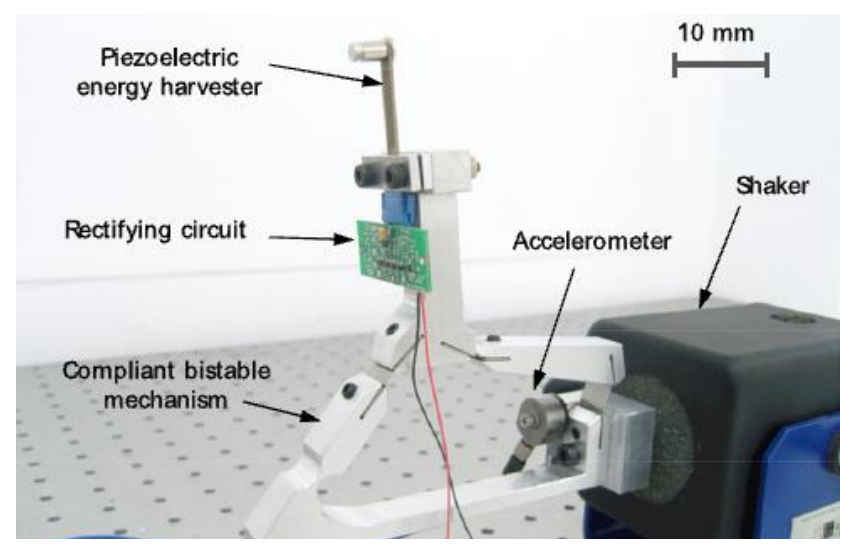

Real harvesting applications are characterized by wide spectrum vibrations [115], with predominance of low frequencies in the case of wearable body harvesters. Non-resonant solutions allow enlarging devices bandwidth and therefore obtain effective harvesting performances, without augmenting devices area or adding power demanding self-tuning features. Moreover, bistable systems show a low-pass behavior that allows harvesting low frequency vibrations without the need for large masses and devices (necessary in resonant cantilevers). Table 3 summarizes the reviewed non-resonant devices and compares their main characteristics. 
Table 3. Comparison of some non-resonant devices. Bistable devices can be benchmarked based on the bistability mechanism. Magnetic repulsion/attraction devices show large bandwidths, but the use of magnets limits technological scaling (magnetic attraction devices require double number of magnets than magnetic repulsion-based harvesters). Buckled beam-based harvesters employ a snap-through mechanism, and are better suited for integration. The main drawback of bistable devices is that they require a particular amount of energy to overcome the potential barrier and switch between the two stable states.

\begin{tabular}{|c|c|c|c|}
\hline Reference & Bistability Mechanism & Advantages & Drawbacks \\
\hline [96] & Magnetic repulsion & $\begin{array}{l}\text { Large bandwidth at low frequencies } \\
\qquad(0 \sim 100 \mathrm{~Hz}) ; \text { MEMS }\end{array}$ & $\begin{array}{c}\text { Input force threshold to achieve bistability; } \\
\text { lower response than resonant device at its } \\
\text { natural frequency }\end{array}$ \\
\hline [105] & Magnetic attraction & High power output at less than $10 \mathrm{~Hz}$ & $\begin{array}{l}\text { Input force threshold to achieve bistability; } \\
\text { lower response than resonant device at its } \\
\text { natural frequency; number of magnets }\end{array}$ \\
\hline [108] & $\begin{array}{c}\text { Clamped-Clamped } \\
\text { buckled beam }\end{array}$ & $\begin{array}{c}\text { No hinges, internal stress or magnets } \\
\text { required; MEMS }\end{array}$ & Input force has to exceed the buckling load \\
\hline [109] & $\begin{array}{c}\text { Simply supported } \\
\text { buckled beam }\end{array}$ & $\begin{array}{l}\text { No hinges, internal stress or magnets } \\
\text { required; improved transduction mechanism }\end{array}$ & Input force has to exceed the buckling load \\
\hline [114] & $\begin{array}{l}\text { Bio-inspired by } \\
\text { auditory system }\end{array}$ & $\begin{array}{l}\text { Snap-through mechanism, independent from } \\
\text { excitation frequency; well suited for } 1 \sim 10 \mathrm{~Hz} \\
\text { harvesting }\end{array}$ & $\begin{array}{l}\text { Advanced mechanical structure with a } \\
\text { commercial piezoelectric harvester }\end{array}$ \\
\hline
\end{tabular}

\section{Rotational Devices}

Although the piezoelectric effect is inherently related to axial elongations, several device configurations were proposed as rotatory harvesters [85,116-125], mainly by transforming a rotatory excitation into a longitudinal strain. Among these, $\mathrm{Gu}$ and Livermore [85] presented a compact self-tuning rotatory harvester, consisting in a rigid piezoelectric beam and a flexible beam with a tip mass at its end (a steel ball). During operation, the steel ball impacts the generating beam, letting it to vibrate. The system natural frequency is determined by the flexible beam natural frequency, which varies with the imposed centrifugal force.

Khameneifar and colleagues $[119,120]$ applied the piezoelectric cantilever concept to a rotating shaft, as shown in Figure 28. This approach allows employing a piezoelectric device for monitoring rotating machines such as turbines or tires. The device (employing a single PZT element with a single $5 \mathrm{~cm}$ length cantilever beam and a $105 \mathrm{~g}$ tip mass) driven at $138 \mathrm{rad} / \mathrm{s}$ was able to harvest $6.4 \mathrm{~mW}$ on an optimum load resistance of $40 \mathrm{k} \Omega$, with a corresponding output voltage of about $16 \mathrm{~V}$.

Pillatsch and colleagues [121] developed a harvester composed of a fixed piezoelectric beam and an eccentric proof mass free to rotate, similar to the Seiko Kinetik watch. This device was designed for human body applications, and was tested on an upper limb during a running task. It was able to harvest up to $43 \mu \mathrm{W}$ at $2 \mathrm{~Hz}$ and $20 \mathrm{~ms}^{-2}$.

Karami and colleagues [122] proposed two configurations of wind turbine, both consisting of a circular array of cantilever beams clamped below a windmill. These beams vibrate in response to the movement of the windmill, which is equipped with repulsive magnets. 
Figure 28. Schematic view of rotatory motion harvester $\left({ }^{\odot} 2013\right.$ IEEE. Reprinted with permission from [120]).

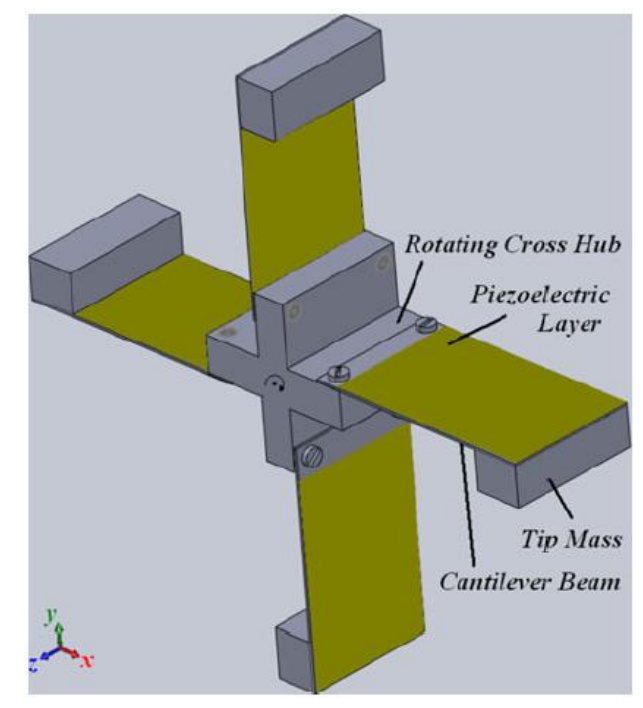

\section{Conditioning Circuitry}

The scientific and technological challenges of energy harvesting systems also deal with power managers. These devices are responsible for transferring harvested energy from generator to a host device and in most cases to a storage element as well. A typical schematic diagram of a power manager is shown in Figure 29.

Figure 29. Typical schematic diagram of a power manager.

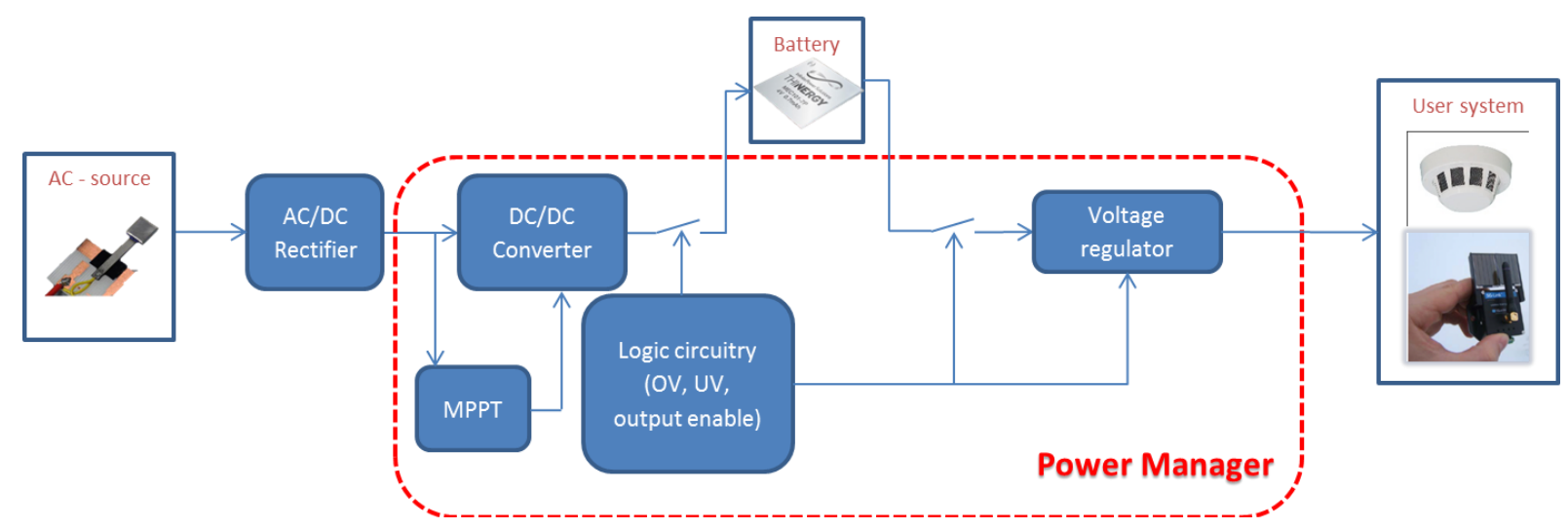

Power managers are designed both for DC and AC sources. They typically employ a DC-DC converter, mainly for impedance matching and also to match the source voltage with the battery charging level. In case of alternate sources, a rectifier is required. In case of direct current sources, impedance matching can be achieved through the use of a maximum power point tracker (MPPT). It implements algorithms apt to follow the input power peaks, which is equivalent to fix the generator operating point by acting on the equivalent impedance of the downstream circuitry. Although MPPT units are suited almost uniquely for DC sources, Yi and colleagues [126] discussed a strategy to implement an energy adaptive algorithm for vibration harvesters. The logic circuitry is designated to control and manage the charge and discharge phases of the battery. Overvoltage and undervoltage 
boundaries can be controlled with the help of comparators and switches. Voltage thresholds are often configurable by users using resistive dividers. Piezoelectric generators are AC sources, hence their output has to be rectified and regulated to supply host devices. The simplest rectifier can be a diode bridge rectifier (Figure 30). The AC-DC converter can be followed by a DC-DC converter, for power optimization and voltage regulation $[127,128]$.

Figure 30. Diode bridge rectifier.

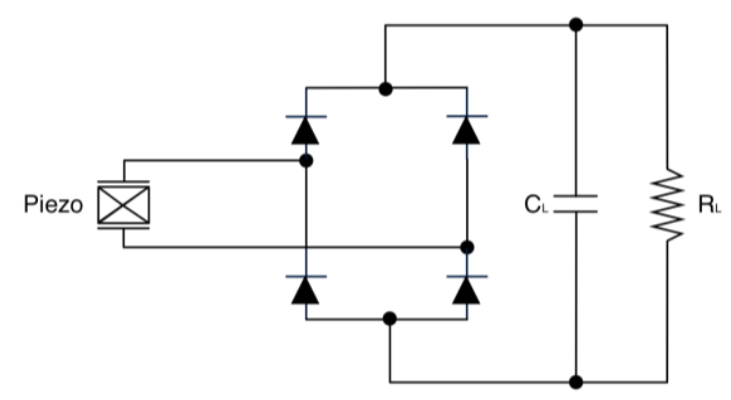

Another possible circuital interface is the parallel-SSHI (synchronized switch harvesting on inductor) [129-131]. This approach allows to enhance the coupling coefficient of the electromechanical system using piezomaterials [130,132-134], it allows to gain up to 10 times in terms of harvested energy [135]. The technique was derived from a semi-passive technique developed for mechanical structures, called SSD (synchronized switch damping) [136-140]. Such configuration adds an inductor-switch branch in parallel to the source (Figure 31).

Figure 31. Parallel-SSHI interface.

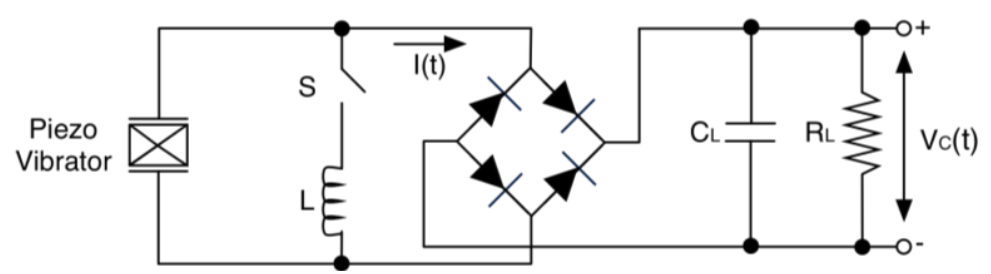

When the device displacement is maximum, the switch is turned ON. In this condition the internal capacitance and the inductor constitute an oscillator, where the characteristic electrical period must be chosen much smaller than the mechanical vibration period. The circuit allows to invert quasi-instantaneously the voltage of the piezoelectric element and thus to put in phase the vibration velocity and the generated voltage [141-143].

A possible implementation of the parallel-SSHI interface consists of two switches, one for the positive half-wave and another one for the negative. The switches are implemented through two MOS transistors driven by the output of a comparator that reads the derivative of the piezoelectric voltage, in order to catch the peak and let the inductor to discharge the parasitic capacitance [131].

This technique allows to dramatically increase the voltage output or to obtain the same output of a standard interface device while reducing the volume of the piezoelectric element.

Based on the same concept, a series-SSHI rectifier consists of an inductor-switch branch added in series to the piezoelectric element, followed by a diode bridge rectifier (Figure 32). The switch control is the same as described above for parallel-SSHI. 
Lefeuvre and colleagues [28] as well reported a synchronous charge extraction interface (Figure 33). The extraction is triggered by the maxima and minima of the displacement $\mathrm{u}$. When the switch is closed, the electrical energy of the internal capacitor is transferred to the inductor, and when the switch is re-opened the energy stored in the inductor is transferred to the downstream smoothing capacitor.

Figure 32. Series-SSHI configuration.

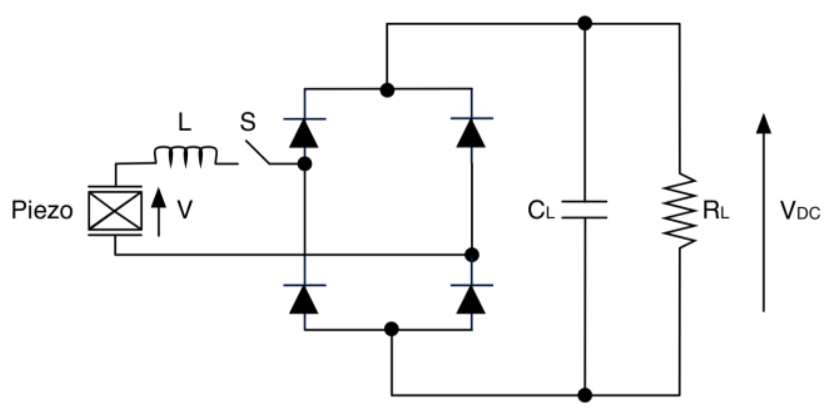

Figure 33. Synchronous charge extraction interface.

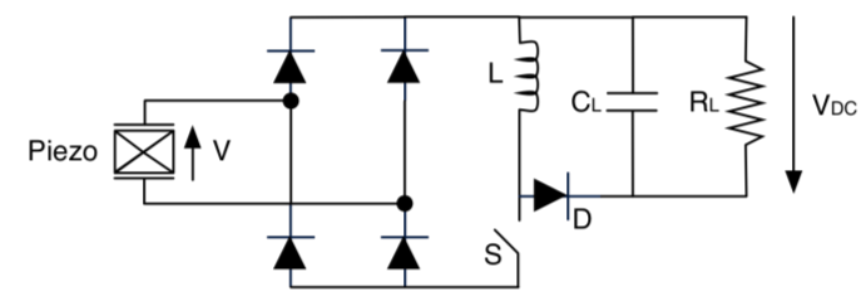

An experimental comparison between these configurations for a constant force amplitude input was presented in [28]. The four techniques have the same maximum harvested power, but at different values of the electromechanical coupling factor. Practically, the synchronous charge extraction technique reaches the maximum at lower electromechanical coupling factors, enabling reduction in required amount of piezoelectric materials, since $k^{2}$ is roughly proportional to the amount of material. Moreover, synchronous charge extraction is indifferent to impedance matching.

Lallart and colleagues [144] developed double synchronized switch harvesting (DSSH) by adding a buck-boost converter to the above described original idea of parallel-SSHI. This one is not driven in a conventional way. Referring to Figure $34, \mathrm{~S}_{2}$ is closed only when $C_{\text {int }}$ is fully charged by the diode bridge rectifier (after every cycle), while $S_{1}$ is $\mathrm{ON}$ when energy on $\mathrm{L}_{2}$ is maximum.

Figure 34. DSSH topology.

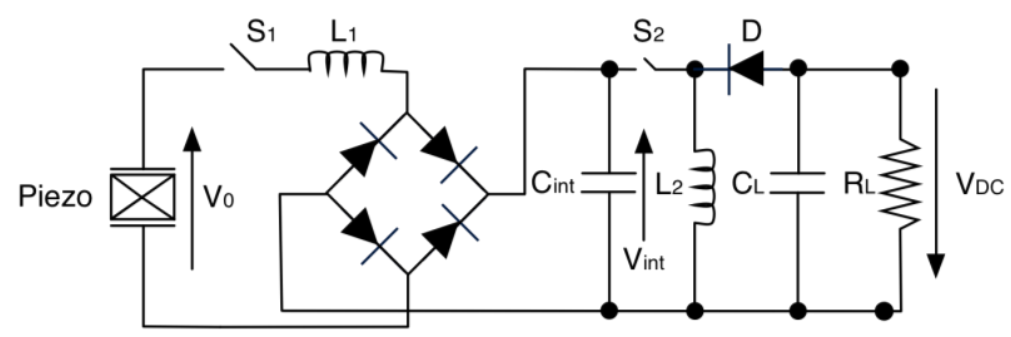


Several other switching techniques were reported by Guyomar and colleagues [142]. All these strategies, however, rely on a deterministic knowledge of the source frequency. If this frequency is time variant or random, the above discussed systems fail.

Giusa and colleagues [145] recently demonstrated a novel approach (called Random mechanical switching harvesting on inductor-RMSHI), which does not require deterministic synchronization. It employs a mechanical switch consisting of two mechanical stoppers. These close the circuit when the beam reaches maximum deflection. Furthermore, the mechanical switch prevents from extra voltage across the inductor, which would occur using an electronic switch.

Commercial solutions are also made available as a result of the research progresses achieved in the last years. Linear Technology (Milpitas, CA, USA) has come up with a series of conditioning devices for energy harvesting. Those circuits are targeted for piezoelectric-based harvesters [146-148] and equipped with low-loss full-wave bridge rectifier followed by a buck or a buck-boost converter. They are also provided with embedded LDOs enabling selectable output voltages, which may also be used to charge batteries.

\section{Conclusions}

Though piezoelectric energy harvesting has been thoroughly investigated since the late 1990s [149], it still remains an emerging technology and critical area of interest. Energy harvesting application fields so far mainly focused on low power devices due to their limited transduction efficiencies [150].

To date, researchers are following distinct ways in developing piezoelectric energy harvesting technology. New materials, configuration approaches and operating modes are under study, and some of these valuable solutions were proposed in order to achieve large bandwidth harvesters that are able to scavenge energy from diverse environments.

Resonant $d_{33}$ cantilever beams need optimization, but several interesting solutions and approaches that were published can push forward the research. $d_{15}$ harvesters are still too complex to be fabricated, but exhibit great potential.

In this review paper these configurations have been briefly studied using a comparison table with respect to $d_{31}$, reporting various factors. From this analysis we can conclude that $d_{15}$ is more efficient than other modes, $d_{33}$ has higher output voltages, simplifying the power conversion process, whereas $d_{31}$ is the simplest solution found in terms of fabrication process and performances (in most cases).

Considering nanoscale harvesters, they represent a promising but still emerging technique that requires to be consolidated. Non-resonant solutions, as well as frequency tuning methods, are powerful instruments to push forward the growth of vibration harvesting techniques. However, though several non-resonant solutions were demonstrated, new roads can be explored. As an example, in electromagnetic vibration harvesting a well-known technique to achieve bistability involves mechanical bumpers [151,152]. Furthermore, all these piezoelectric harvesting research branches could be merged. Likely, a bistable harvester involving a high efficiency $d_{15}$ material, equipped with a proper conditioning circuitry, would achieve significant results.

The limit in terms of harvested energy density has still to be overcome. This has been the main technological challenge so far. A well-integrated roadmap was designed in the framework of the Guardian Angels Coordination Action within the Future and Emerging Technologies Flagship 
initiative funded by the European Commission [153]. In this framework, research efforts are focusing on the transducer and also on the integration with the downstream conditioning circuitry, power management circuits and application devices.

\section{Acknowledgments}

This work was supported in part by the NanoBioTouch European project (Nano-resolved multi-scale investigations of human tactile sensations and tissue engineered nanobiosensors; EU-FP7-NMP-228844), by the PRIN/HandBot Italian project (Biomechatronic hand prostheses endowed with bio-inspired tactile perception, bi-directional neural interfaces and distributed sensori-motor control; CUP: B81J12002680008; prot.: 20102YF2RY) by the SensAlone Working Capital Grant awarded by Telecom Italia (Self-powered Stand-Alone Sensing System), and by Scuola Superiore Sant'Anna.

The authors would like to thank Francesca Spagnuolo for support in getting permissions to reproduce some of the figures integrated in the manuscript.

\section{Author Contributions}

This paper has been written thanks to the intensive work of each author. Renato Caliò was the main responsible of the bibliographic search and analysis and Calogero Maria Oddo was the scientific coordinator of the study. Renato Caliò and Calogero Maria Oddo wrote the paper and worked on each section of the present manuscript. Udaya Bhaskar Rongala gave important contributions in Sections 2 and 4.1. Domenico Camboni wrote several parts along Section 4, while Mario Milazzo and Cesare Stefanini contributed mainly in Sections 4.2 and 6. Gianluca de Petris contributed mainly to the discussion of application scenarios in Sections 1 and 10. All the authors helped in reviewing and deeply analyzing the manuscript until its final version.

\section{Conflicts of Interest}

The authors declare no conflicts of interest.

\section{References}

1. Torah, R.; Glynne-Jones, P.; Tudor, M.; O’Donnell, T.; Roy, S.; Beeby, S. Self-powered autonomous wireless sensor node using vibration energy harvesting. Meas. Sci. Technol. 2008, 19, 125202.

2. Magno, M.; Boyle, D.; Brunelli, D.; O’Flynn, B.; Popovici, E.; Benini, L. Extended wireless monitoring through intelligent hybrid energy supply. IEEE Trans. Ind. Electron. 2014, 61, 1871-1881.

3. Anton, S.R.; Inman, D.J. Vibration energy harvesting for unmanned aerial vehicles. In Proceedings of the 15th International Symposium on Smart Structures and Materials \& Nondestructive Evaluation and Health Monitoring, San Diego, CA, USA, 9-13 March 2008; doi:10.1117/12.774990.

4. Chapuis, A.; Jaquet, E.; Grandvoinet, R.S. The History of the Self-Winding Watch, 1770-1931; Éditions du Griffon: Gloucestershire, UK, 1956. 
5. Paradiso, J.A.; Hsiao, K.Y.; Benbasat, A.Y.; Teegarden, Z. Design and implementation of expressive footwear. IBM Syst. J. 2000, 39, 511-529.

6. Mateu, L.; Fonellosa, F.; Moll, F. Electrical characterization of a piezoelectric film-based power generator for autonomous werable devices. In Proceedings of the XVIII Conference on Design of Circuits and Integrated Systems, Ciudad Real, Spain, November 2003; Volume 18.

7. Mateu, L.; Moll, F. Optimum piezoelectric bending beam structures for energy harvesting using shoe inserts. J. Intell. Mater. Syst. Struct. 2005, 16, 835-845.

8. Paradiso, J.A.; Starner, T. Energy scavenging for mobile and wireless electronics. IEEE Pervas. Comput. 2005, 4, 18-27.

9. Lucarotti, C.; Oddo, C.M.; Vitiello, N.; Carrozza, M.C. Synthetic and bio-artificial tactile sensing: A review. Sensors 2013, 13, 1435-1466.

10. Jornet, J.M.; Akyildiz, I.F. Joint energy harvesting and communication analysis for perpetual wireless nanosensor networks in the terahertz band. IEEE Trans. Nanotechnol. 2012, 11, 570-580.

11. Allameh, S.M.; Akogwu, O.; Collinson, M.; Thomas, J.; Soboyejo, W.O. Piezoelectric generators for biomedical and dental applications: Effects of cyclic loading. J. Mater. Sci. 2007, $18,39-45$.

12. Yang, Y.; Zhang, H.; Lin, Z.-H.; Zhou, Y.S.; Jing, Q.; Su, Y.; Yang, J.; Chen, J.; Hu, C.; Wang, Z.L. Human skin based triboelectric nanogenerators for harvesting biomechanical energy and as self-powered active tactile sensor system. ACS Nano 2013, 7, 9213-9222.

13. Hosoda, K.; Tada, Y.; Asada, M. Anthropomorphic robotic soft fingertip with randomly distributed receptors. Robot. Auton. Syst. 2006, 54, 104-109.

14. Oddo, C.M.; Controzzi, M.; Beccai, L.; Cipriani, C.; Carrozza, M.C. Roughness encoding for discrimination of surfaces in artificial active-touch. IEEE Trans. Robot. 2011, 27, 522-533.

15. Tanner, K. Titanium in medicine. J. Eng. Med. Inst. Mech. Eng. Proc. 2001, 216, 215.

16. Dagdeviren, C.; Yang, B.D.; Su, Y.; Tran, P.L.; Joe, P.; Anderson, E.; Xia, J.; Doraiswamy, V.; Dehdashti, B.; Feng, X.; et al. Conformal piezoelectric energy harvesting and storage from motions of the heart, lung, and diaphragm. Proc. Natl. Acad. Sci. USA 2014, 111, 1927-1932.

17. Starner, T. Human-powered wearable computing. IBM Syst. J. 1996, 35, 618-629.

18. Worthington, E.L. Techniques, Piezoelectric Energy Harvesting: Enhancing Power Output by Device Optimization and Circuit; Cranfield University: Bedford, UK, 2010.

19. Mhetre, M.R.; Nagdeo, N.S.; Abhyankar, H.K. Micro energy harvesting for biomedical applications: A review. In Proceedings of the IEEE 2011 3rd International Conference on Electronics Computer Technology (ICECT), Kanyakumari, India, 8-10 April 2011; Volume 3, pp. 1-5.

20. Roundy, S.; Wright, P.K.; Rabaey, J. A study of low level vibrations as a power source for wireless sensor nodes. Comput. Commun. 2003, 26, 1131-1144.

21. Beeby, S.P.; Tudor, M.J.; White, N. Energy harvesting vibration sources for microsystems applications. Meas. Sci. Technol. 2006, 17, R175-R195.

22. Wikipedia: Vitruvian Man. Available online: http://en.wikipedia.org/wiki/File:Da_Vinci_ Vitruve_Luc_Viatour.jpg (accessed on 28 February 2014).

23. Fukada, E.; Yasuda, I. On the piezoelectric effect of bone. J. Phys. Soc. Jpn. 1957, 12, 1158-1162.

24. Jaffe, B. Piezoelectric Ceramics (Vol. 3); Academic Press: London, UK, 1971. 
25. The Piezoelectric Effect. Available online: http://www.aurelienr.com/electronique/piezo/piezo.pdf (accessed on 28 February 2014).

26. 176-1987-IEEE Standard on Piezoelectricity. Available online: http://ieeexplore.ieee.org/xpl/ login.jsp?tp=\&arnumber=26560\&url=http\%3A\%2F\%2Fieeexplore.ieee.org\%2Fxpls\%2Fabs_all. jsp\%3Farnumber\%3D26560 (accessed on 28 February 2014).

27. Richards, C.D.; Anderson, M.J.; Bahr, D.F.; Richards, R.F. Efficiency of energy conversion for devices containing a piezoelectric component. J. Micromech. Microeng. 2004, 14, 717-721.

28. Lefeuvre, E.; Badel, A.; Richard, C.; Petit, L.; Guyomar, D. A comparison between several vibration-powered piezoelectric generators for standalone systems. Sens. Actuators A Phys. 2006, $126,405-416$.

29. Priya, S.; Inman, D.J. Energy Harvesting Technologies; Springer: Berlin, Germany, 2009.

30. Baldisserri, C.; Gardini, D.; Galassi, C. Sharp silicon/lead zirconate titanate interfaces by electrophoretic deposition on bare silicon wafers and post-deposition sintering. Sens. Actuators A Phys. 2012, 174, 123-132.

31. Koka, A.; Zhou, Z.; Sodano, H.A. Vertically aligned batio3 nanowire arrays for energy harvesting. Energy Environ. Sci. 2014, 7, 288-296.

32. Anton, S.R.; Sodano, H.A. A review of power harvesting using piezoelectric materials (2003-2006). Smart Mater. Struct. 2007, 16, R1.

33. Shen, D.; Choe, S.Y.; Kim, D.J. Analysis of piezoelectric materials for energy harvesting devices under high-g vibrations. Jpn. J. Appl. Phys. 2007, 46, 6755-6760.

34. Kranz, B.; Benjeddou, A.; Drossel, W.G. Numerical and experimental characterizations of longitudinally polarized piezoelectric d15 shear macro-fiber composites. Acta Mech. 2013, 224, $1-17$.

35. Wang, Z.L.; Song, J. Piezoelectric nanogenerators based on zinc oxide nanowire arrays. Science 2006, 312, 242-246.

36. Wang, Z.L.; Song, J. Supporting Online Material for Piezoelectric Nanogenerators Based on Zinc Oxide Nanowire Arrays. Available online: http://www.sciencemag.org/content/suppl/2006/04/13/ 312.5771.242.DC1/WangZ.SOM.pdf (accessed on 28 February 2014).

37. Morgan-Electro-Ceramics Tp-226 Properties of Piezoelectricity Ceramics. Available online: http://traktoria.org/files/sonar/piezoceramics/morgan/properties_of_piezoelectric_ceramics_\%28 pzt-4_pzt-5a_pzt-5h_pzt-8\%29.pdf (accessed on 28 February 2014).

38. Ferroperm-Piezoceramics Ferroperm Data Matrix. Available online: http://www.ferropermpiezo.com/ (accessed on 28 February 2014).

39. Channel-Industries-Inc. Piezoelectric Ceramics. Available online: http://www.channelindustries.com/ _includes/chan_cat.pdf (accessed on 28 February 2014).

40. Peng, J.; Luo, H.S.; Lin, D.; Xu, H.Q.; He, T.H.; Jin, W.Q. Orientation dependence of transverse piezoelectric properties of $0.70 \mathrm{~Pb}\left(\mathrm{Mg}_{1 / 3} \mathrm{Nb}_{2 / 3}\right) O_{3}-0.30 \mathrm{PbTiO}_{3}$ single crystals. Appl. Phys. Lett. 2004, 85, 6221-6223.

41. Zhang, S.; Li, F.; Sherlock, N.P.; Luo, J.; Lee, H.J.; Xia, R.; Meyer, R.J., Jr.; Hackenberger, W.; Shrout, T.R. Recent developments on high Curie temperature PIN-PMN-PT ferroelectric crystals. J. Cryst. Growth 2011, 318, 846-850. 
42. Peng, J.; Chen, J.; Luo, H.; He, T.; Xu, H.; Lin, D. Shear-mode piezoelectric properties of $0.69 \mathrm{~Pb}\left(\mathrm{Mg}_{1 / 3} \mathrm{Nb}_{2 / 3}\right) \mathrm{O}_{3}-0.31 \mathrm{PbTiO}_{3}$ single crystals. Solid State Commun. 2004, 130, 53-57.

43. Ferrari, M.; Ferrari, V.; Guizzetti, M.; Marioli, D.; Taroni, A. Piezoelectric multifrequency energy converter for power harvesting in autonomous microsystems. Sens. Actuators A Phys. 2008, 142, 329-335.

44. Erturk, A.; Inman, D.J. Issues in mathematical modeling of piezoelectric energy harvesters. Smart Mater. Struct. 2008, 17, 065016.

45. Williams, C.; Yates, R.B. Analysis of a micro-electric generator for microsystems. Sens. Actuators A Phys. 1996, 52, 8-11.

46. Gafforelli, G. Energy Harvesting: State of Art. Available online: ftp://ftp.stru.polimi.it/incoming/ gafforelli/Energy\%20Harvesting/Pres_EH-State\%20of\%20art.pdf (accessed on 28 February 2014).

47. Roundy, S.; Leland, E.S.; Baker, J.; Carleton, E.; Reilly, E.; Lai, E.; Otis, B.; Rabaey, J.M.; Wright, P.K.; Sundararajan, V. Improving power output for vibration-based energy scavengers. IEEE Pervas. Comput. 2005, 4, 28-36.

48. Ng, T.H. Sensitivity analysis and energy harvesting for a self-powered piezoelectric sensor. J. Intell. Mater. Syst. Struct. 2005, 16, 785-797.

49. Lu, F.; Lee, H.P.; Lim, S.P. Modeling and analysis of micro piezoelectric power generators for micro-electromechanical-systems applications. Smart Mater. Struct. 2004, 13, 57-63.

50. Yang, R.; Qin, Y.; Dai, L.; Wang, Z.L. Power generation with laterally packaged piezoelectric fine wires. Nat. Nano 2009, 4, 34-39.

51. Umeda, M.; Nakamura, K.; Ueha, S. Analysis of the transformation of mechanical impact energy to electric energy using piezoelectric vibrator. Jpn. J. Appl. Phys. 1996, 35, 3267-3273.

52. Umeda, M.; Nakamura, K.; Ueha, S. Energy storage characteristics of a piezo-generator using impact induced vibration. Jpn. J. Appl. Phys. 1997, 36, 3146-3151.

53. Xu, C.N.; Akiyama, M.; Nonaka, K.; Watanabe, T. Electrical power generation characteristics of PZT piezoelectric ceramics. IEEE Trans. Ultrason. Ferroelectr. Freq. Control 1998, 45, 1065-1070.

54. Funasaka, T.; Furuhata, M.; Hashimoto, Y.; Nakamura, K. Piezoelectric generator using a $\mathrm{LiNbO}_{3}$ plate with an inverted domain. Proc. IEEE Ultrason. Symp. 1998, 1, 959-962.

55. Chure, M.C.; Wu, L.; Wu, K.K.; Tung, C.C.; Lin, J.S.; Ma, W.C. Power generation characteristics of PZT piezoelectric ceramics using drop weight impact techniques: Effect of dimensional size. Ceramics Int. 2014, 40, 341-345.

56. Chidambaram, N.; Mazzalai, A.; Muralt, P. Measurement of effective piezoelectric coefficients of PZT thin films for energy harvesting application with interdigitated electrodes. IEEE Trans. Ultrason. Ferroelectr. Freq. Control 2012, 59, 1624-1631.

57. Kim, S.B.; Park, H.; Kim, S.H.; Wikle, H.C.; Park, J.H.; Kim, D.J. Comparison of MEMS PZT cantilevers based on $d_{31}$ and $d_{33}$ modes for vibration energy harvesting. J. Microelectromech. Syst. 2013, 22, 26-33.

58. Bowen, C.R.; Nelson, L.J.; Stevens, R.; Cain, M.G.; Stewart, M. Optimisation of interdigitated electrodes for piezoelectric actuators and active fibre composites. J. Electroceram. 2006, 16, 263-269.

59. Paradies, R.; Melnykowycz, M.M. State of stress in piezoelectric elements with interdigitated electrodes. J. Electroceram. 2010, 24, 137-144. 
60. Knight, R.R.; Mo, C.; Clark, W.W. MEMS interdigitated electrode pattern optimization for a unimorph piezoelectric beam. J. Electroceram. 2011, 26, 14-22.

61. Jeon, Y.; Sood, R.; Jeong, J.-H.; Kim, S.-G. MEMS power generator with transverse mode thin film PZT. Sens. Actuators A Phys. 2005, 122, 16-22.

62. Choi, W.; Jeon, Y.; Jeong, J.-H.; Sood, R.; Kim, S.-G. Energy harvesting MEMS device based on thin film piezoelectric cantilevers. J. Electroceram. 2006, 17, 543-548.

63. Park, J.H.; Ahn, H.; Kim, S.B.; Kim, S.H.; Kim, D.J. Comparison of transduction efficiency for energy harvester between piezoelectric modes. In MEMS and Nanotechnology, Volume 2; Proulx, T., Ed.; Springer: New York, NY, USA, 2010; pp. 33-39.

64. Kim, S.B.; Park, J.H.; Kim, S.H.; Ahn, H.; Wikle, H.C.; Kim, D.J. Fabrication and analytical modeling of transverse mode piezoelectric energy harvesters. MRS Proc. 2011, 1397, 84-89.

65. Shen, Z.; Liu, S.; Miao, J.; Woh, L.S.; Wang, Z. Proof mass effects on spiral electrode $d_{33}$ mode piezoelectric diaphragm-based energy harvester. In Proceedings of the IEEE International Conference on Micro Electro Mechanical Systems (MEMS), Taipei, Taiwan, 20-24 January 2013; pp. 821-824.

66. Han, M.; Chan, Y.C.; Liu, W.; Zhang, S.; Zhang, H. Low frequency PVDF piezoelectric energy harvester with combined d31 and d33 operating modes. In Proceedings of the IEEE NEMS 8th Annual IEEE International Conference on Nano/Micro Engineered and Molecular Systems, Suzhou, China, 7-10 April 2013; pp. 440-443.

67. Zhou, Y.; Yang, S.C.; Apo, D.J.; Maurya, D.; Priya, S. Tunable self-biased magnetoelectric response in homogenous laminates. Appl. Phys. Lett. 2012, 101, 232905.

68. Zhou, Y.; Apo, D.J.; Priya, S. Dual-phase self-biased magnetoelectric energy harvester. Appl. Phys. Lett. 2013, 103, 192909.

69. Delnavaz, A.; Voix, J. Energy harvesting for in-ear devices using ear canal dynamic motion. IEEE Trans. Ind. Electron. 2014, 61, 583-590.

70. Piezo Sensor-Metallized Film Sheets. Available online: http://www.meas-spec.com/product/ t_product.aspx?id=2488 (accessed on 28 February 2014).

71. Sun, C.; Shi, J.; Bayerl, D.J.; Wang, X. PVDF microbelts for harvesting energy from respiration. Energy Environ. Sci. 2011, 4, 4508-4512.

72. Qi, Y.; Jafferis, N.T.; Lyons, K., Jr.; Lee, C.M.; Ahmad, H.; McAlpine, M.C. Piezoelectric ribbons printed onto rubber for flexible energy conversion. Nano Lett. 2010, 10, 524-528.

73. Qi, Y.; Kim, J.; Nguyen, T.D.; Lisko, B.; Purohit, P.K.; McAlpine, M.C. Enhanced piezoelectricity and stretchability in energy harvesting devices fabricated from buckled PZT ribbons. Nano Lett. 2011, 11, 1331-1336.

74. Ren, B.; Or, S.; Wang, F.; Zhao, X.; Luo, H.; Li, X.; Zhang, Q.; Di, W.; Zhang, Y. Piezoelectric energy harvesting based on shear mode $0.71 \mathrm{~Pb}\left(\mathrm{Mg}_{1 / 3} \mathrm{Nb}_{2 / 3}\right) \mathrm{O}_{3}-0.29 \mathrm{PbTiO}_{3}$ single crystals. IEEE Trans. Ultrason. Ferroelectr. Freq. Control 2010, 57, 1419-1425.

75. Majidi, C.; Haataja, M.; Srolovitz, D.J. Analysis and design principles for shear-mode piezoelectric energy harvesting with zno nanoribbons. Smart Mater. Struct. 2010, 19, 055027.

76. Wang, D.A.; Liu, N.Z. A shear mode piezoelectric energy harvester based on a pressurized water flow. Sens. Actuators A Phys. 2011, 167, 449-458. 
77. Zhao, J.; Zheng, X.; Zhou, L.; Zhang, Y.; Sun, J.; Dong, W.; Deng, S.; Peng, S. Investigation of a d15 mode PZT-51 piezoelectric energy harvester with a series connection structure. Smart Mater. Struct. 2012, 21, 105006.

78. Marzencki, M.; Ammar, Y.; Basrour, S. Integrated power harvesting system including a MEMS generator and a power management circuit. Sens. Actuators A Phys. 2007, 145-146, 887-890.

79. Xu, S.; Qin, Y.; Xu, C.; Wei, Y.; Yang, R.; Wang, Z.L. Self-powered nanowire devices. Nat. Nanotechnol. 2010, 5, 366-373.

80. Lee, S.; Bae, S.H.; Lin, L.; Yang, Y.; Park, C.; Kim, S.W.; Cha, S.N.; Kim, H.; Park, Y.J.; Wang, Z.L. Super-flexible nanogenerator for energy harvesting from gentle wind and as an active deformation sensor. Adv. Funct. Mater. 2013, 23, 2445-2449.

81. Baker, J.; Roundy, S.; Wright, P. Alternative geometries for increasing power density in vibration energy scavenging for wireless sensor networks. In Proceedings of the 3rd International Energy Conversion Engineering Conference, San Francisco, CA, USA, August 2005; Volume 2, pp. 959-970.

82. Goldschmidtboeing, F.; Woias, P. Characterization of different beam shapes for piezoelectric energy harvesting. J. Micromech. Microeng. 2008, 18, 104013.

83. Marzencki, M.; Basrour, S.; Charlot, B. Design, modelling and optimisation of integrated piezoelectric micro power generators. In Proceedings of the 2005 NSTI Nanotechnology Conference and Trade Show-NSTI Nanotech 2005 Technical Proceedings, Anaheim, CA, USA, 8-12 May 2005; pp. 545-548.

84. Gu, L.; Livermore, C. Passive self-tuning energy harvester for extracting energy from rotational motion. Appl. Phys. Lett. 2010, 97, 081904.

85. Gu, L.; Livermore, C. Compact passively self-tuning energy harvesting for rotating applications. Smart Mater. Struct. 2012, 21, 015002.

86. Challa, V.R.; Prasad, M.G.; Fisher, F.T. Towards a self-tunable, wide frequency bandwidth vibration energy harvesting device. In Proceedings of the ASME International Mechanical Engineering Congress and Exposition, Vancouver, BC, Canada, 12-18 November 2010; Volume 6, pp. 57-65.

87. Roundy, S.; Zhang, Y. Toward self-tuning adaptive vibration based micro-generators. Proc. SPIE 2005, 5649, 373-384.

88. Eichhorn, C.; Tchagsim, R.; Wilhelm, N.; Woias, P. A smart and self-sufficient frequency tunable vibration energy harvester. J. Micromech. Microeng. 2011, 21, 1-11.

89. Lallart, M.; Anton, S.R.; Inman, D.J. Frequency self-tuning scheme for broadband vibration energy harvesting. J. Intell. Mater. Syst. Struct. 2010, 21, 897-906.

90. Peters, C.; Maurath, D.; Schock, W.; Mezger, F.; Manoli, Y. A closed-loop wide-range tunable mechanical resonator for energy harvesting systems. J. Micromech. Microeng. 2009, 19, 094004.

91. Wischke, M.; Masur, M.; Goldschmidtboeing, F.; Woias, P. Electromagnetic vibration harvester with piezoelectrically tunable resonance frequency. J. Micromech. Microeng. 2010, 20, 035025.

92. Eichhorn, C.; Goldschmidtboeing, F.; Woias, P.; Porro, Y.; Woias, P. A piezoelectric harvester with an integrated frequency-tuning mechanism. Power MEMS 2009, 45-48. 
93. Liu, J.-Q.; Fang, H.-B.; Xu, Z.-Y.; Mao, X.-H.; Shen, X.-C.; Chen, D.; Liao, H.; Cai, B.-C. A MEMS-based piezoelectric power generator array for vibration energy harvesting. Microelectron. J. 2008, 39, 802-806.

94. Cottone, F.; Vocca, H.; Gammaitoni, L. Nonlinear energy harvesting. Phys. Rev. Lett. 2009, 102, $1-14$.

95. Stanton, S.C.; McGehee, C.C.; Mann, B.P. Nonlinear dynamics for broadband energy harvesting: Investigation of a bistable piezoelectric inertial generator. Phys. D Nonlinear Phenom. 2010, 239 , 640-653.

96. Andò, B.; Baglio, S.; Trigona, C.; Dumas, N.; Latorre, L.; Nouet, P. Nonlinear mechanism in MEMS devices for energy harvesting applications. J. Micromech. Microeng. 2010, 20, 1-12.

97. Lin, J.T.; Alphenaar, B. Enhancement of energy harvested from a random vibration source by magnetic coupling of a piezoelectric cantilever. J. Intell. Mater. Syst. Struct. 2010, 21, 1337-1341.

98. Vocca, H.; Neri, I.; Travasso, F.; Gammaitoni, L. Kinetic energy harvesting with bistable oscillators. Appl. Energy 2012, 97, 771-776.

99. Tang, L.; Yang, Y.; Soh, C.K. Improving functionality of vibration energy harvesters using magnets. J. Intell. Mater. Syst. Struct. 2012, 23, 1433-1449.

100. Stanton, S.C.; McGehee, C.C.; Mann, B.P. Reversible hysteresis for broadband magnetopiezoelastic energy harvesting. Appl. Phys. Lett. 2009, 95, 174103.

101. Harmer, G.P.; Davis, B.R.; Abbott, D. A review of stochastic resonance: Circuits and measurement. IEEE Trans. Instrum. Meas. 2002, 51, 299-309.

102. Bulsara, A.R.; Gammaitoni, L. Tuning in to noise. Phys. Today 1996, 49, 39.

103. Gammaitoni, L.; Bulsara, A. Noise activated nonlinear dynamic sensors. Phys. Rev. Lett. 2002, 88, 230601.

104. Litak, G.; Friswell, M.I.; Adhikari, S. Magnetopiezoelastic energy harvesting driven by random excitations. Appl. Phys. Lett. 2010, 96, 214103.

105. Erturk, A.; Inman, D.J. Broadband piezoelectric power generation on high-energy orbits of the bistable duffing oscillator with electromechanical coupling. J. Sound Vib. 2011, 330, 2339-2353.

106. Casals-Terre, J.; Fargas-Marques, A.; Shkel, A.M. Snap-action bistable micromechanisms actuated by nonlinear resonance. J. Microelectromech. Syst. 2008, 17, 1082-1093.

107. Boyle, P.; Moore, D.; Breen, R.; Syms, R.; Zou, H.; Stagg, J. MEMS bistable clamp with electrical locking and release. In Proceedings of the 15th Micromechanics Workshop (MME'04), Leuven, Belgium, 5-7 September 2004; pp. 45-48.

108. Qiu, J.; Lang, J.H.; Slocum, A.H. A curved-beam bistable mechanism. J. Microelectromech. Syst. 2004, 13, 137-146.

109. Xu, C.; Liang, Z.; Ren, B.; Di, W.; Luo, H.; Wang, D.; Wang, K.; Chen, Z. Bi-stable energy harvesting based on a simply supported piezoelectric buckled beam. J. Appl. Phys. 2013, 114, 114507.

110. Arrieta, A.F.; Hagedorn, P.; Erturk, A.; Inman, D.J. A piezoelectric bistable plate for nonlinear broadband energy harvesting. Appl. Phys. Lett. 2010, 97, 104102.

111. Cottone, F.; Gammaitoni, L.; Vocca, H.; Ferrari, M.; Ferrari, V. Piezoelectric buckled beams for random vibration energy harvesting. Smart Mater. Struct. 2012, 21, 035021. 
112. Andò, B.; Baglio, S.; L’Episcopo, G.; Trigona, C. Investigation on Mechanically Bistable MEMS Devices for Energy Harvesting from Vibrations. J. Microelectromech. Syst. 2012, 21, 779-790.

113. Andò, B.; Baglio, S.; Maiorca, F.; Trigona, C. Analysis of two dimensional, wide-band, bistable vibration energy harvester. Sens. Actuators A Phys. 2013, 202, 176-182.

114. Kim, G.W.; Kim, J. Compliant bistable mechanism for low frequency vibration energy harvester inspired by auditory hair bundle structures. Smart Mater. Struct. 2013, 22, 014005.

115. Neri, I.; Travasso, F.; Mincigrucci, R.; Vocca, H.; Orfei, F.; Gammaitoni, L. A real vibration database for kinetic energy harvesting application. J. Intell. Mater. Syst. Struct. 2012, 23, 2095-2101.

116. Myers, R.; Vickers, M.; Kim, H.; Priya, S. Small scale windmill. Appl. Phys. Lett. 2007, 90, 054106.

117. Tien, C.M.T.; Goo, N.S. Use of a piezo-composite generating element for harvesting wind energy in an urban region. Aircr. Eng. Aerosp. Technol. 2010, 82, 376-381.

118. Bressers, S.; Avirovik, D.; Lallart, M.; Inman, D.J.; Priya, S. Contact-Less Wind Turbine Utilizing Piezoelectric Bimorphs with Magnetic Actuation. In Structural Dynamics, Volume 3; Proulx, T., Ed.; Springer: New York, NY, USA, 2011; pp. 233-243.

119. Khameneifar, F.; Moallem, M.; Arzanpour, S. Modeling and analysis of a piezoelectric energy scavenger for rotary motion applications. J. Vib. Acousti. 2011, 133, 011005.

120. Khameneifar, F.; Arzanpour, S.; Moallem, M. A piezoelectric energy harvester for rotary motion applications: Design and experiments. IEEE/ASME Trans. Mechatron. 2013, 18, 1527-1534.

121. Pillatsch, P.; Yeatman, E.M.; Holmes, A.S. A wearable piezoelectric rotational energy harvester. In Proceedings of the 2013 IEEE International Conference on Body Sensor Networks (BSN 2013), Cambridge, MA, USA, 6-9 May 2013; pp. 1-9.

122. Karami, M.A.; Farmer, J.R.; Inman, D.J. Parametrically excited nonlinear piezoelectric compact wind turbine. Renew. Energy 2013, 50, 977-987.

123. Khaligh, A.; Zeng, P.; Zheng, C. Kinetic energy harvesting using piezoelectric and electromagnetic technologies - state of the art. IEEE Trans. Ind. Electron. 2010, 57, 850-860.

124. Oliver, J.R.; Neurgaonkar, R.R.; Moffatt, A.P.; Khoshnevisan, M.; Nelson, J.G. Piezoelectric Energy Harvester and Method. U.S. Patent 6,407,484, 18 June 2002.

125. Priya, S. Advances in energy harvesting using low profile piezoelectric transducers. J. Electroceram. 2007, 19, 167-184.

126. Yi, J.; Su, F.; Lam, Y.H.; Ki, W.H.; Tsui, C.Y. An Energy-Adaptive Mppt Power Management Unit for Micro-Power Vibration Energy Harvesting. In Proceedings of IEEE International Symposium on Circuits and Systems (ISCAS 2008), Seattle, WA, USA, 18-21 May 2008; pp. 2570-2573.

127. Ottman, G.K.; Hofmann, H.F.; Bhatt, A.C.; Lesieutre, G.A. Adaptive piezoelectric energy harvesting circuit for wireless remote power supply. IEEE Trans. Power Electron. 2002, 17, 669-676.

128. Ottman, G.K.; Hofmann, H.F.; Lesieutre, G.A. Optimized piezoelectric energy harvesting circuit using step-down converter in discontinuous conduction mode. IEEE Trans. Power Electron. 2003, 18, 696-703. 
129. Lefeuvre, E.; Badel, A.; Richard, C.; Guyomar, D. High-Performance Piezoelectric Vibration Energy Reclamation. In Smart Structures and Materials; International Society for Optics and Photonics: San Diego, CA, USA, 2004; pp. 379-387.

130. Guyomar, D.; Badel, A.; Lefeuvre, E.; Richard, C. Toward energy harvesting using active materials and conversion improvement by nonlinear processing. IEEE Trans. Ultrason. Ferroelectr. Freq. Control 2005, 52, 584-595.

131. Grace, E.A.; Rajan, S.E.; Asis, A.A.C. Performance evaluation of different rectifiers for piezo-electric energy harvesting applications. In Proceedings of the IEEE 2011 International Conference on Recent Advancements in Electrical, Electronics and Control Engineering (ICONRAEeCE), Sivakasi, Indian, 15-17 December 2011; pp. 248-252.

132. Makihara, K.; Onoda, J.; Miyakawa, T. Low energy dissipation electric circuit for energy harvesting. Smart Mater. Struct. 2006, 15, 1493.

133. Qiu, J.; Jiang, H.; Ji, H.; Zhu, K. Comparison between four piezoelectric energy harvesting circuits. Front. Mech. Eng. China 2009, 4, 153-159.

134. Qiu, J.; Ji, H.; Shen, H. Energy harvesting and vibration control using piezoelectric elements and a nonlinear approach. In Proceedings of the 18th IEEE International Symposium on the Applications of Ferroelectrics (ISAF 2009), Xi'an, China, 23-27 August 2009; pp. 1-8.

135. Guyomar, D.; Sebald, G.; Pruvost, S.; Lallart, M.; Khodayari, A.; Richard, C. Energy harvesting from ambient vibrations and heat. J. Intell. Mater. Syst. Struct. 2009, 20, 609-624.

136. Badel, A.; Sebald, G.; Guyomar, D.; Lallart, M.; Lefeuvre, E.; Richard, C.; Qiu, J. Piezoelectric vibration control by synchronized switching on adaptive voltage sources: Towards wideband semi-active damping. J. Acoust. Soc. Am. 2006, 119, 2815.

137. Badel, A.; Lagache, M.; Guyomar, D.; Lefeuvre, E.; Richard, C. Finite element and simple lumped modeling for flexural nonlinear semi-passive damping. J. Intell. Mater. Syst. Struct. 2007, 18, 727-742.

138. Lallart, M.; Lefeuvre, É.; Richard, C.; Guyomar, D. Self-powered circuit for broadband, multimodal piezoelectric vibration control. Sens. Actuators A Phys. 2008, 143, 377-382.

139. Shen, H.; Qiu, J.; Ji, H.; Zhu, K.; Balsi, M.; Giorgio, I.; Dell'Isola, F. A low-power circuit for piezoelectric vibration control by synchronized switching on voltage sources. Sens. Actuators A Phys. 2010, 161, 245-255.

140. Ji, H.; Qiu, J.; Xia, P. Analysis of energy conversion in two-mode vibration control using synchronized switch damping approach. J. Sound Vib. 2011, 330, 3539-3560.

141. Shu, Y.; Lien, I.; Wu, W. An improved analysis of the SSHI interface in piezoelectric energy harvesting. Smart Mater. Struct. 2007, 16, 2253.

142. Guyomar, D.; Lallart, M. Recent progress in piezoelectric conversion and energy harvesting using nonlinear electronic interfaces and issues in small scale implementation. Micromachines 2011, 2, 274-294.

143. Garbuio, L.; Lallart, M.; Guyomar, D.; Richard, C.; Audigier, D. Mechanical energy harvester with ultralow threshold rectification based on SSHI nonlinear technique. IEEE Trans. Ind. Electron. 2009, 56, 1048-1056. 
144. Lallart, M.; Garbuio, L.; Petit, L.; Richard, C.; Guyomar, D. Double synchronized switch harvesting (DSSH): A new energy harvesting scheme for efficient energy extraction. IEEE Trans. Ultrason. Ferroelectr. Freq. Control 2008, 55, 2119-2130.

145. Giusa, F.; Giuffrida, A.; Trigona, C.; Andò, B.; Bulsara, A.R.; Baglio, S. Random mechanical switching harvesting on inductor: A novel approach to collect and store energy from weak random vibrations with zero voltage threshold. Sens. Actuators A Phys. 2013, 198, 35-45.

146. LTC3588-1-Piezoelectric Energy Harvesting Power Supply. Available online: http://www. linear.com/product/LTC3588-1 (accessed on 28 February 2014).

147. LTC3588-2 - Piezoelectric Energy Harvesting Power Supply with 14 V Minimum VIN. Available online: http://www.linear.com/product/LTC3588-2 (accessed on 28 February 2014).

148. LTC3330 - Nanopower Buck-Boost DC/DC with Energy Harvesting Battery Life Extender. Available online: http://www.linear.com/product/LTC3330 (accessed on 28 February 2014).

149. White, N.M.; Glynne-Jones, P.; Beeby, S.P. A novel thick-film piezoelectric micro-generator. Smart Mater. Struct. 2001, 10, 850-852.

150. Mitcheson, P.D.; Yeatman, E.M.; Rao, G.K.; Holmes, A.S.; Green, T.C. Energy harvesting from human and machine motion for wireless electronic devices. Proc. IEEE 2008, 96, 1457-1486.

151. Accoto, D.; Castrataro, P.; Montagna, G.; Pellegrini, A.; Sabatini, M.; Scarfogliero, U.; Stefanini, C. Miniaturised Generator for the Production of Electrical Energy from Vibrations. Patent Wo2008062377 A3, 6 November 2008.

152. Stefanini, C.; Castrataro, P.; Accoto, D. Miniaturized Generator with Oscillating Magnets for the Production of Electric Energy from Vibrations. Patent Wo2010041186 a1, 15 April 2010.

153. Guardian-Angels Zero Power Systems. Available online: http://www.ga-project.eu/ (accessed on 28 February 2014).

(C) 2014 by the authors; licensee MDPI, Basel, Switzerland. This article is an open access article distributed under the terms and conditions of the Creative Commons Attribution license (http://creativecommons.org/licenses/by/3.0/). 